Atmos. Chem. Phys., 10, 1473-1490, 2010

www.atmos-chem-phys.net/10/1473/2010/

(C) Author(s) 2010. This work is distributed under

the Creative Commons Attribution 3.0 License.

\title{
Aerosol distribution around Svalbard during intense easterly winds
}

\author{
A. Dörnbrack ${ }^{1}$, I. S. Stachlewska ${ }^{2,3}$, C. Ritter ${ }^{3}$, and R. Neuber ${ }^{3}$ \\ ${ }^{1}$ DLR Oberpfaffenhofen, Institut für Physik der Atmosphäre, 82230 Wessling, Germany \\ ${ }^{2}$ Institute of Geophysics, Faculty of Physics, University of Warsaw, Pasteura 7, 02-093 Warsaw, Poland \\ ${ }^{3}$ Alfred-Wegener Institut für Polar- und Meeresforschung (AWI), Forschungsstelle Potsdam, Telegraphenberg 43A, \\ 14473 Potsdam, Germany
}

Received: 30 June 2009 - Published in Atmos. Chem. Phys. Discuss.: 5 August 2009

Revised: 18 December 2009 - Accepted: 21 January 2010 - Published: 15 February 2010

\begin{abstract}
This paper reports on backscatter and depolarization measurements by an airborne lidar in the Arctic during the ASTAR 2004 campaign. A unique weather situation facilitated the observation of the aerosol concentration under strongly forced atmospheric conditions. The vigorous easterly winds distorted the flow past Svalbard in such a way that mesoscale features were visible in the remote-sensing observations: The formation of a well-mixed aerosol layer inside the Adventdalen and the subsequent thinning of the aerosol plume were observed over the Isfjorden. Additionally, mobilization of sea salt aerosols due to a coastal low-level jet at the northern tip of Svalbard resulted in a sloped boundary layer toward north. Mesoscale numerical modelling was applied to identify the sources of the aerosol particles and to explain the observed patterns.
\end{abstract}

\section{Introduction}

In the Arctic, properties of tropospheric aerosol particles have been measured in numerous field studies beginning in the 1970s (Radke et al., 1984; Schnell, 1984; Schnell et al., 1989; Thomason et al., 2003; Treffeisen et al., 2004; Yamanouchi et al., 2005). Knowledge of the spatial and seasonal distribution of aerosol particles is needed to estimate the induced changes in the Earth radiative budget via direct (e.g. Schwartz and Andrea, 1996; Rinke et al., 2004; Ritter et al., 2005) and indirect (e.g. Garrett et al., 2002; Lubin and Vogelmann, 2006) effects on the solar $(0.3-5 \mu \mathrm{m})$ and

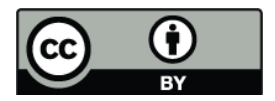

Correspondence to: A. Dörnbrack (andreas.doernbrack@dlr.de) thermal-infrared $(5-50 \mu \mathrm{m})$ radiation. In many instances, the interpretation of observed aerosol particle distributions, especially in the vicinity of complex topography or near the ice edge, requires to know the meso- and microscale atmospheric state. However, this knowledge might not be sufficient as the additionally needed aerosol particle sources and their composition are often not well characterized.

We report about airborne remote-sensing observations made in the vicinity of Svalbard during the ASTAR $2004^{1}$ field campaign. During ASTAR 2004 an airborne lidar was employed to investigate the Arctic aerosol distribution in the lowermost troposphere around Svalbard. In the period from 18-21 May 2004, the lidar observations revealed an exceptional high aerosol concentration in the fjord system and in the lee of Svalbard. However, as reported by Engvall et al. (2008) the background aerosol load was exceptionally low at the time of the observations. Grund-based insitu observations at the Zeppelin station (Ny Ålesund, $79^{\circ} \mathrm{N}$, $12^{\circ} \mathrm{E}$ ) during the ASTAR 2004 campaign encountered "even less contaminated conditions than usual at this time of the year". During late spring, average particles concentrations of about $500 \mathrm{~cm}^{-3}$ for particles larger than $10 \mathrm{~nm}$ and less than $10 \mathrm{~cm}^{-3}$ for particles larger than $260 \mathrm{~nm}$ were observed, see Table 2 in Engvall et al. (2008).

Therefore, the question arises if the observed enhanced aerosol backscatter mainly resulted from local sources which could not impact the observations at Ny Ålesund. The distinct mesoscale pattern of the vertical profiles of aerosol backscatter ratio at the different measurement locations support this hypothesis. Indeed, the flow situation during the

\footnotetext{
${ }^{1}$ ASTAR 2004 - Arctic Study of Tropospheric Aerosol, Clouds and Radiation - was organized by the Alfred-Wegner Institut für Polar- und Meeresforschung Bremerhaven; see http://www.awi.de.
}

Published by Copernicus Publications on behalf of the European Geosciences Union. 
period of the airborne observations was very exceptional. A slowly moving cyclone between northern Scandinavia and Svalbard and a stationary anticyclone north of $80^{\circ} \mathrm{N}$ caused a strong easterly flow across the islands. Usually, easterly winds prevail in winter according to Skeie and Grønås (2000). Easterly winds past Svalbard are associated with clouds blocked at the eastern upstream side of the islands, strong valley flows and a significant flow distortion around Svalbard. Especially, the descending winds in the lee clear the atmosphere downstream. Thus, this particular situation allowed airborne observations of the aerosol distribution under strongly forced meteorological conditions in the fjord system and in the lee of Svalbard.

One goal of this paper is to explain these different mesoscale aerosol patterns of the airborne lidar observations. For this purpose, operational meteorological analyses of the European Centre of Medium Range Weather Forecast (ECMWF) and high-resolution numerical simulations are applied. In particular, the geophysical fluid solver EULAG (Prusa et al., 2008) has been expanded by three transport equations for scalar quantities representing different sources of aerosol particles. Additionally, the observed vertical aerosol distributions are utilized to study the characteristics of the atmospheric flow around and over Svalbard.

Previous numerical simulations of the mesoscale flow around Svalbard concentrated on the impact on the local weather forecast, especially on ship routing. For example, Sandvik and Furevik (2002) highlighted the enormous effect Svalbards topography plays in modifying the local wind field in the valleys and coastal areas surrounding the islands. These authors reported downstream coastal jets with maximum velocities up to 3 times the value of the upstream flow. Furthermore, they argued that these local wind systems influence the high-latitude air-sea interaction processes in a significant way by increasing the surface fluxes of heat and constituents in a simular manner as it is observed over the Irminger Sea east of Greenland (Pickart et al., 2003).

The remaining parts of the paper are arranged as follows: the next section presents the airborne lidar observations and characterizes the aerosol particles by backscatter ratio and depolarization. Section 3 presents the mesoscale numerical simulations. Section 4 discusses the results of the present study to what extent meteorological factors explain the observed distribution of aerosol particles.

\section{Airborne lidar observations}

The airborne aerosol backscatter observations were obtained with the Airborne Mobile Aerosol Lidar AMALi (for the instrument specification, see Appendix A) onboard the AWIPOLAR 2 research aircraft ${ }^{2}$ during the ASTAR 2004 cam-

\footnotetext{
${ }^{2}$ The AWI research aircraft POLAR 2 and 4 were the primary platforms for the ASTAR 2004 experiment. The aircraft were operating from Longyearbyen airport on Svalbard from 10 May 2004
}

paign (17 May-10 June 2004). Data analysed here were collected under nearly clear-sky conditions in the Adventdalen, the Isfjorden, and in the coastal areas west of Svalbard in the period from 18 to 21 May 2004.

\subsection{Meteorological conditions}

Figure 1 illustrates the meteorological situation in terms of temperature, geopotential height and wind speed at the $925 \mathrm{hPa}$ pressure surface on the three measurement days. The maps are based on operational analyses of the European Centre of Medium Range Weather Forecast (ECMWF) with a spectral resolution of $T_{\mathrm{L}} 511$ and 60 vertical hybrid $\sigma$ p levels. On 18 and 19 May 2004, prevailing cold easterly winds with $T<263 \mathrm{~K}$ at $925 \mathrm{hPa}$ were present over Svalbard (Fig. 1a, b). In response to this flow, descending air formed a warm pool ( $T \approx 267 \mathrm{~K}$ at $925 \mathrm{hPa}$ on 19 May 2004, Fig. 1b, c) in the wake region west of Prins Karls Foreland. Additionally and most remarkably, the flow around the islands resulted in a detached low-level jet with a horizontal wind speed of $V_{\mathrm{H}}>15 \mathrm{~m} \mathrm{~s}^{-1}$ emanating from the northern tip of Svalbard, a phenomen similar to Greenland's tip jet (e.g. Doyle and Shapiro, 1999; Orr et al., 2005).

The Moderate-Resolution Imaging Spectroradiometer (MODIS) satellite imagery (Fig. 2) illustrates the meteorological analyses by a snapshot from 19 May 2004 at 12:00 UTC: A cloud-free "Foehn" gap extended from the west coast of Svalbard about half of the width of archipelago downstream. There, the brightness temperature difference to the upstream value amounts to $\Delta \mathrm{LST} \approx 7 \mathrm{~K}$, where $\mathrm{LST}$ is the land-surface temperature (Fig. 2c). The white and peach-colored structures indicate cloud systems at different altitudes (Fig. 2b): Low-level clouds existed all around the islands. Especially, they appeared as rather compact and nearly east-west oriented bands over the pack-ice north of Svalbard. Upper-level cirrus mark the warm sector of the approaching trough over the Barents Sea that propagated slowly north-eastward. Associated with the low-level jet north of Svalbard, a nearly cloud-free wake extended several hundred kilometer downstream (cf. also NOAA AVHRR on 19 May 2004 at 14:41 UTC at http://www.sat.dundee.ac.uk).

On 19 May 2004, the horizontal wind speed $V_{\mathrm{H}}$ upstream of the northern parts of Svalbard varied between 8 and $13 \mathrm{~m} \mathrm{~s}^{-1}$ in the lower troposphere and there was no significant directional shear across the boundary layer, cf. Fig. 3. Given an upstream mean buyoancy frequency of $N=0.01 \mathrm{~s}^{-1}$ and a $V_{\mathrm{H}} \approx 10 \mathrm{~m}^{-1}$ results in an inverse Froude number $\mathcal{F}^{-1}=N h_{0} / V_{\mathrm{H}} \approx 0.5 \ldots 1.6$ for typical maximum elevations of the orography $h_{0}$ between 500 and $1600 \mathrm{~m}$. Another dimensionsless number describing the flow regime is the Rossby number $\mathcal{R}=V_{\mathrm{H}} / L f$, where $L$ is the mountain width and $f$ the Coriolis parameter. Taking a typial mountain width $L$ of $50 \ldots 100 \mathrm{~km}$, this results in Rossby

until 18 June 2004; for more detailed information visit http://www. awi.de. 


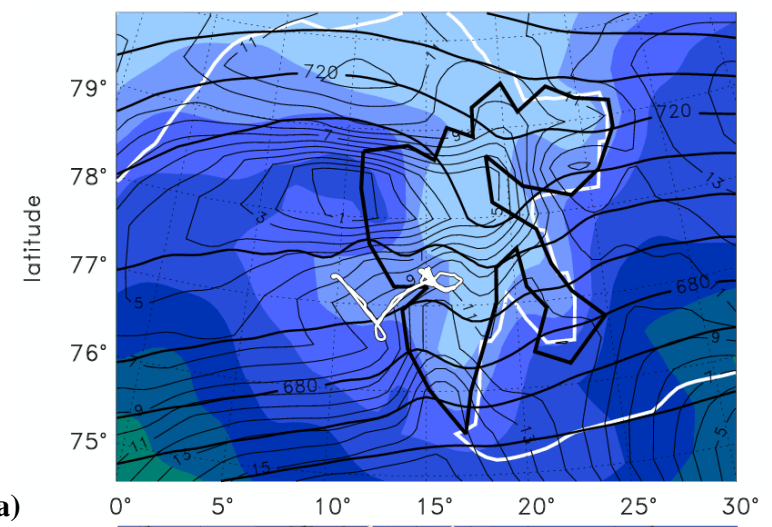

(a)

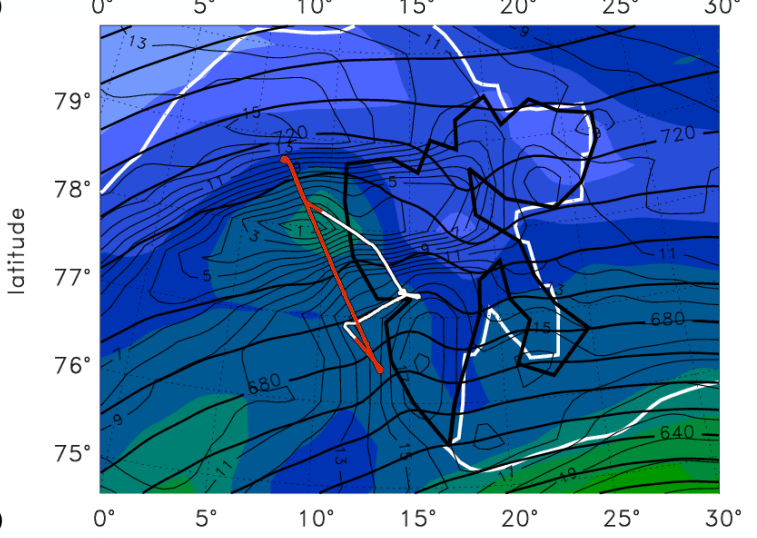

(b)

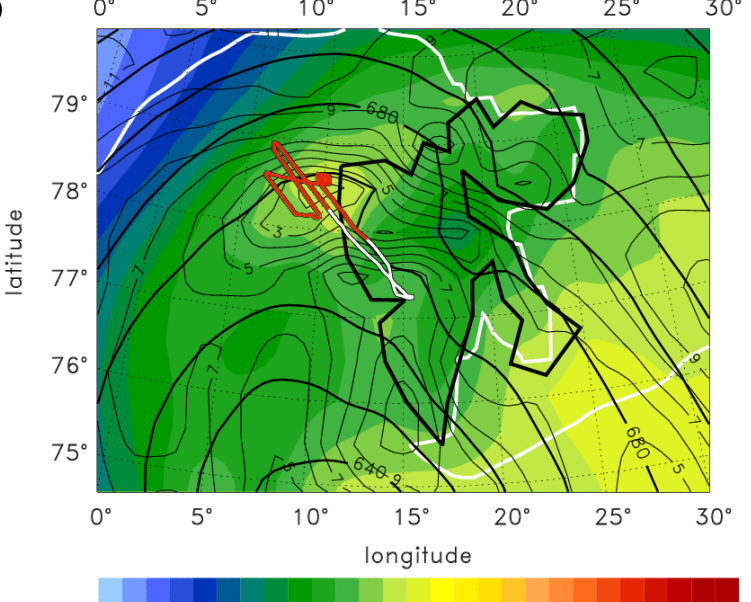

(c)

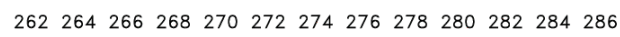

Fig. 1. Temperature (K, color shaded), geopotential height ( $\mathrm{m}$; thick solid lines), and horizontal wind speed $\left(\mathrm{ms}^{-1}\right.$, thin solid lines) on the $925 \mathrm{hPa}$ pressure surface at 18 May 2004 12:00 UTC (a), 19 May 2004 12:00 UTC (b), and at 21 May 2004 18:00 UTC (c). The wind is parallel to the contour lines of the geopotential height and points in the direction having low values to the left. Data are operational $T_{\mathrm{L}} 511 / \mathrm{L} 60 \mathrm{ECMWF}$ analyses interpolated on a regular $0.5 \times 0.5$ latitude-longitude grid. The thick white line marks the analysed ice edge. The flight paths of the Polar 2 research aircraft are marked by white and red lines. The red segments mark the sections shown in Fig. 7. For the locations of the Adventdalen and Isfjorden, please refer to Fig. 4.

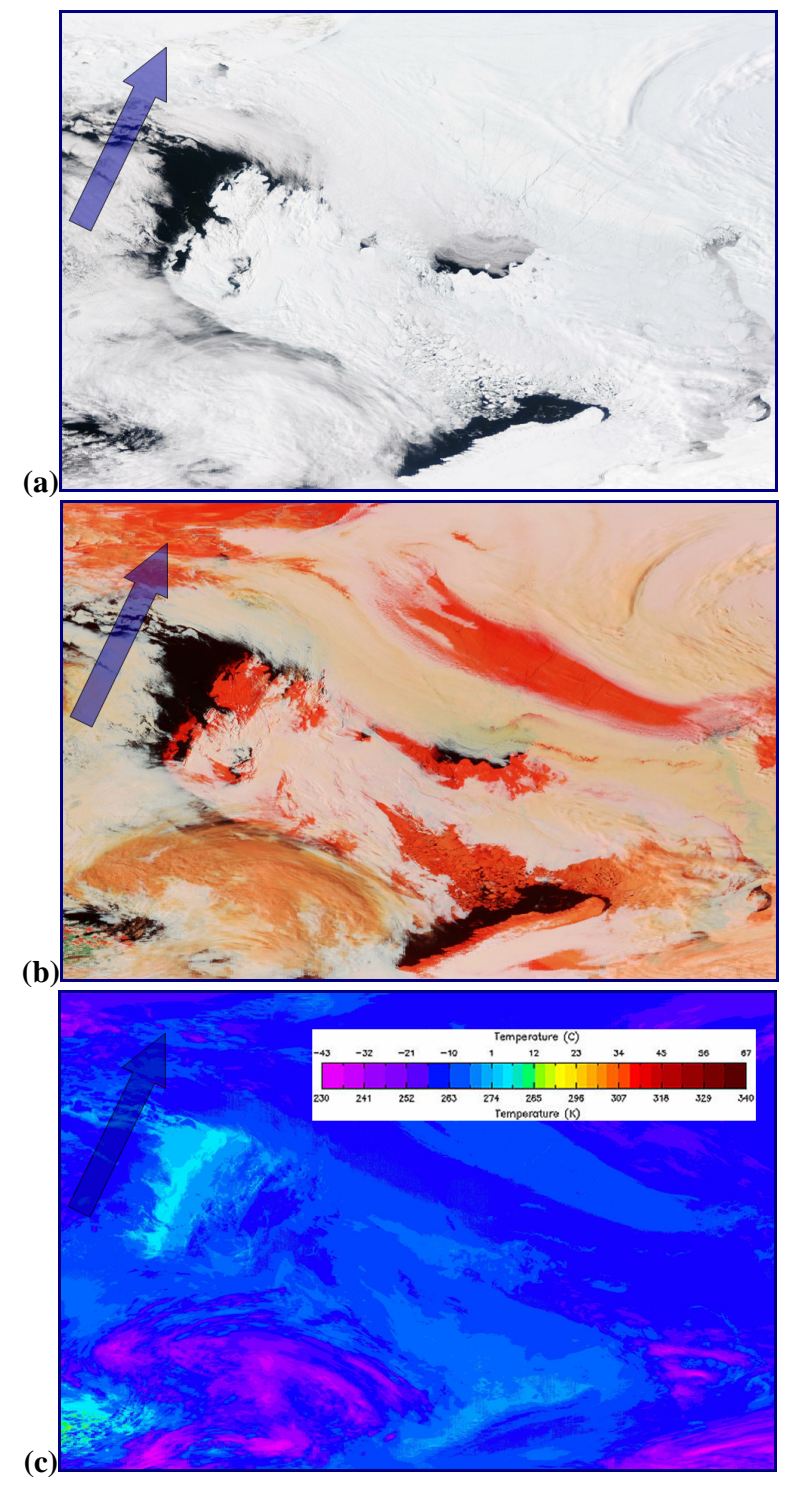

Fig. 2. MODIS satellite imagery of channels $1,4,3(670 \mathrm{~nm}$, $565 \mathrm{~nm}$, and $479 \mathrm{~nm}$ ) so-called true color (a), of channels 3, 6, 7 $(479 \mathrm{~nm}, 1.652 \mathrm{~nm}$, and $2.155 \mathrm{~nm})$ the red colors $(\mathbf{b})$, and the land surface temperature (c) valid on 19 May 2004 at 12:00 UTC. In the red channels ice and snow cover appear as red, liquid water on the ground as black, liquid water clouds as white and ice clouds as peach. The west coast of Svalbard is cloud free and visible at the east side of the Foehn gap located right of the northward pointing arrow. Image courtesy of MODIS Rapid Response Project at NASA/GSFC: http://rapidfire.sci.gsfc.nasa.gov. 

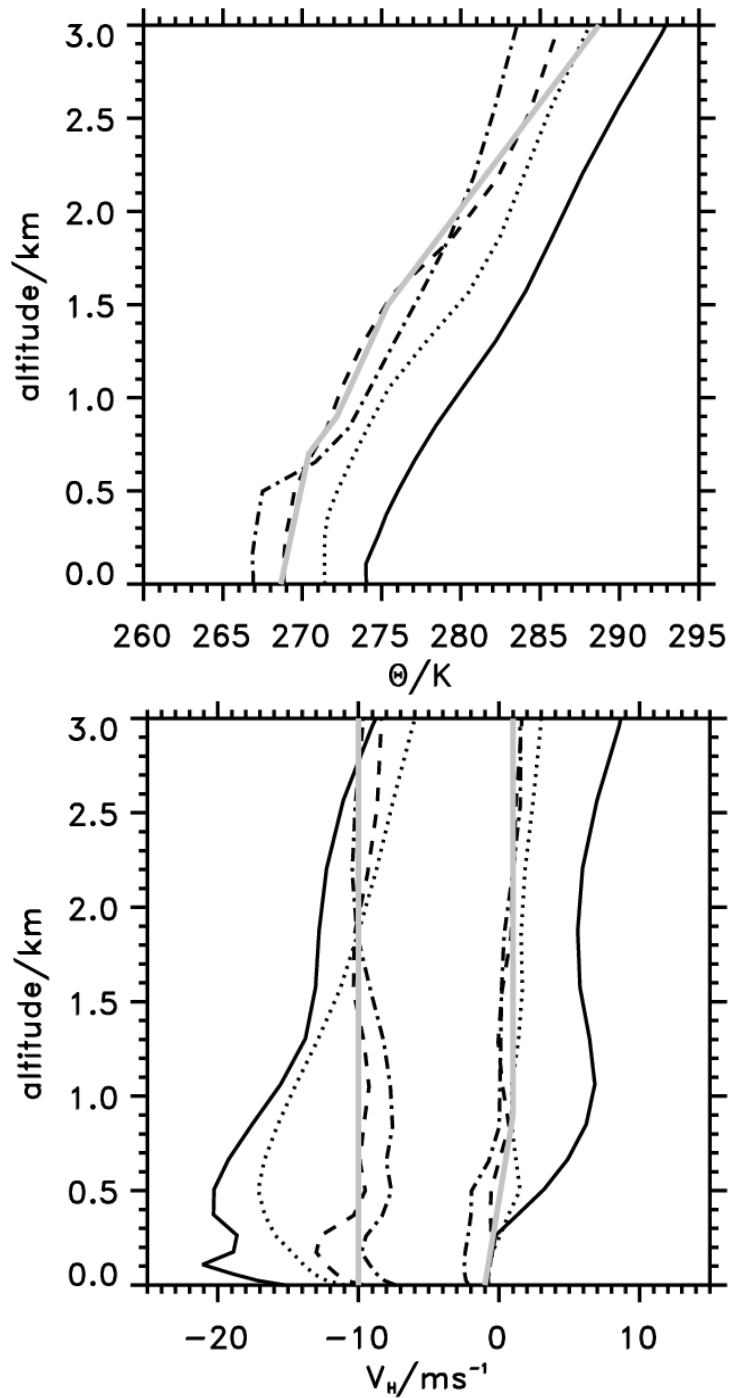

Fig. 3. Upstream profiles of potential temperature $\Theta$ (upper panel) and the zonal (all profiles negative values) and meridional wind speed at $30^{\circ} \mathrm{E}$ and $75^{\circ} \mathrm{N}$ (solid line), $77^{\circ} \mathrm{N}$ (dotted line), $79^{\circ} \mathrm{N}$ (dashed line), and at $81^{\circ} \mathrm{N}$ (dash-dotted line) valid at 19 May 2004 12:00 UTC. Meteorological data are based on operational $T_{\mathrm{L}}$ 511/L60 ECMWF analyses. The bold grey lines mark the initial conditions of the EULAG simulations.

numbers between 0.7 and 1.4. According to a regime diagram (see Schär, 2002), the resulting flow is expected to be partially around and over Svalbard. Furthermore, for $\mathcal{R F}^{-1} \geq 0.5$, balanced solutions (e.g. based on geostrophy or quasi-geostrophy) break down due to the splitting of the incident low-lewel flow upstream (Pierrehumbert, 1985). This justifies the usage of non-hydrostatic numerical simulations later on in this paper.

At the end of the observational period, the warm front of the approaching trough resulted in weaker winds, now blowing from south-east (Fig. 1c). In the meteorological anal- yses for 21 May 2004, the low-level jet north of Svalbard still existed, however, with a magnitude of about 7 to $9 \mathrm{~m} \mathrm{~s}^{-1}$ it was significantly weaker (Fig. 1c). The warm pool and the wake shifted slightly northwards due to the enhanced southerly wind component. As the upstream sea-surface temperature remained nearly constant during the period, the associated warm air advection (upstream temperature increased by about $9 \mathrm{~K}$ at $925 \mathrm{~K}$ during the three days) enhanced the thermal stratification dramatically in the marine boundary layer.

The preconditions of the three research flights during this period differed markedly: Whereas the legs of both flights on 19 and 21 May 2004 were designed after a meticulous meteorological planning to map the aerosol distribution downstream of Svalbard, the very first flight on 18 May 2004 (see flight legs in Fig. 1) was performed rather spontaneously after the unexpected occurence of a dust storm in the Adventdalen.

\subsection{Dust storm in adventdalen}

On 18 May 2004, significant loads of mineral dust ${ }^{3}$ were mobilized by the strong winds blowing through the snow-free Adventdalen. With the prevailing easterly winds, these particles were transported along the valley toward the Isfjorden (see MODIS imagery on http://rapidfire.sci.gsfc.nasa.gov at 18 May 2004 03:35 UTC and pictures at subsequent times covering Svalbard). Generally, events like this are more common in autum, when most of Svalbard's valleys are free of snow. However, the dry and sunny conditions during the preceeding weeks in April and May 2004 melted/evaporated the snow layer in the Adventdalen. Essentially, the flight legs on 18 May 2004 were flown to record the dispersion of the dust plume from its source region inside the valley to the mouth of the Isfjorden, see Fig. 4.

Figures 5 and 6 depict profiles of the averaged and highpass filtered backscatter ratio $R_{532 \mathrm{~nm}}$ and volume depolarization $\delta_{532} \mathrm{~nm}$ taken at 17 selected segments along the flight track, for details see Table 1 . The backscatter ratio is a measure of the number of the backscattering particles whereas the depolarization provides the particles' asphericity. We start our discussion with the profiles along the east-west section through the Advensdalen (see Fig. 4b).

The profiles measured in the eastern part of the valley (Fig. 5 a, b) show two distinct characteristics. The easternmost profile (number 17) shows $R_{532 \mathrm{~nm}}>100$ near the surface and an exponential decrease towards the ambient value of $R_{532 \mathrm{~nm}} \approx 1.4$ above $400 \mathrm{~m}$ over ground. This ambient $R_{532} \mathrm{~nm}$-value derives from lidar observations at $\mathrm{Ny}$ Ålesund (Hoffmann et al., 2009) and constitutes an average for low tropospheric altitudes in the absence of clouds or

\footnotetext{
${ }^{3}$ In addition to the sand from the dry river bed also coal particles can be found in the Adventdalen. There, the transport from the active coal mines in the eastern part of valley toward the harbor leads to an emission of coal particles along the valley road.
} 
Table 1. Locations of the 17 areas where the vertical aerosol backscatter and depolarization profiles were calculated. The area number refers to the colored boxes in Fig. 3. This table lists the coordinates of the respective areas and the observation times of the AMALi observations that were used to average the vertical backscatter and depolarization profiles as shown in Figs. 4 and 5.

\begin{tabular}{|c|c|c|c|}
\hline Area No & $\lambda_{\mathrm{MIN}} / \lambda_{\mathrm{MAX}}$ & $\phi_{\mathrm{MIN}} / \phi_{\mathrm{MAX}}$ & Times/UTC \\
\hline 1 & $11.58^{\circ} \mathrm{E} / 11.65^{\circ} \mathrm{E}$ & $77.93^{\circ} \mathrm{N} / 77.97^{\circ} \mathrm{N}$ & 11:01:19-11:02:09, 11:33:24-11:33:47 \\
\hline 2 & $11.79^{\circ} \mathrm{E} / 11.86^{\circ} \mathrm{E}$ & $77.87^{\circ} \mathrm{N} / 77.91^{\circ} \mathrm{N}$ & 10:59:39-11:00:09, 11:35:13-11:35:46 \\
\hline 3 & $11.93^{\circ} \mathrm{E} / 12.00^{\circ} \mathrm{E}$ & $77.84^{\circ} \mathrm{N} / 77.88^{\circ} \mathrm{N}$ & $10: 58: 23-10: 59: 02,11: 36: 24-11: 36: 57$ \\
\hline 4 & $12.29^{\circ} \mathrm{E} / 12.36^{\circ} \mathrm{E}$ & $77.76^{\circ} \mathrm{N} / 77.78^{\circ} \mathrm{N}$ & $11: 39: 29-11: 40: 04,11: 51: 56-11: 52: 29$ \\
\hline 5 & $13.30^{\circ} \mathrm{E} / 13.70^{\circ} \mathrm{E}$ & $78.00^{\circ} \mathrm{N} / 78.17^{\circ} \mathrm{N}$ & $10: 44: 01-10: 47: 10,12: 02: 23-12: 05: 10$ \\
\hline 6 & $14.10^{\circ} \mathrm{E} / 14.50^{\circ} \mathrm{E}$ & $78.15^{\circ} \mathrm{N} / 78.25^{\circ} \mathrm{N}$ & $10: 38: 12-10: 40: 49,12: 07: 44-12: 10: 17$ \\
\hline 7 & $14.95^{\circ} \mathrm{E} / 15.11^{\circ} \mathrm{E}$ & $78.27^{\circ} \mathrm{N} / 78.29^{\circ} \mathrm{N}$ & $10: 34: 32-10: 35: 27,12: 13: 09-12: 14: 06$ \\
\hline 8 & $15.11^{\circ} \mathrm{E} / 15.24^{\circ} \mathrm{E}$ & $78.28^{\circ} \mathrm{N} / 78.30^{\circ} \mathrm{N}$ & $\begin{array}{l}10: 33: 51-10: 34: 30,12: 14: 08-12: 14: 20 \\
12: 32: 35-12: 32: 42\end{array}$ \\
\hline 9 & $15.20^{\circ} \mathrm{E} / 15.38^{\circ} \mathrm{E}$ & $78.31^{\circ} \mathrm{N} / 78.34^{\circ} \mathrm{N}$ & $\begin{array}{l}09: 14: 35-09: 15: 31,09: 20: 08-09: 21: 04 \\
10: 00: 39-10: 01: 37,10: 07: 36-10: 08: 09 \\
10: 25: 20-10: 26: 12,10: 32: 19-10: 33: 09\end{array}$ \\
\hline 10 & $15.39^{\circ} \mathrm{E} / 15.42^{\circ} \mathrm{E}$ & $78.28^{\circ} \mathrm{N} / 78.31^{\circ} \mathrm{N}$ & $\begin{array}{l}09: 21: 48-09: 22: 00,09: 43: 12-09: 43: 30 \\
09: 43: 42-09: 43: 51,10: 00: 09-10: 00: 27 \\
10: 08: 24-10: 08: 29,10: 24: 28-10: 24: 28\end{array}$ \\
\hline 11 & $15.52^{\circ} \mathrm{E} / 15.62^{\circ} \mathrm{E}$ & $78.22^{\circ} \mathrm{N} / 78.28^{\circ} \mathrm{N}$ & $\begin{array}{l}09: 22: 49-09: 23: 35,09: 44: 54-09: 45: 36 \\
09: 58: 07-09: 59: 03,10: 09: 53-10: 10: 49 \\
10: 22: 28-10: 23: 07,12: 16: 48-12: 17: 33 \\
12: 29: 40-12: 30: 17\end{array}$ \\
\hline 12 & $15.62^{\circ} \mathrm{E} / 15.72^{\circ} \mathrm{E}$ & $78.21^{\circ} \mathrm{N} / 78.25^{\circ} \mathrm{N}$ & $\begin{array}{l}09: 23: 36-09: 24: 16,09: 45: 37-09: 46: 20 \\
09: 57: 22-09: 58: 05,10: 10: 51-10: 11: 44 \\
10: 21: 55-10: 22: 27,12: 17: 35-12: 18: 14 \\
12: 29: 03-12: 29: 39\end{array}$ \\
\hline 13 & $15.72^{\circ} \mathrm{E} / 15.82^{\circ} \mathrm{E}$ & $78.19^{\circ} \mathrm{N} / 78.22^{\circ} \mathrm{N}$ & $\begin{array}{l}09: 24: 54-09: 24: 55,09: 46: 21-09: 47: 02 \\
09: 56: 43-09: 57: 21,10: 11: 45-10: 12: 27 \\
10: 21: 20-10: 21: 53,10: 18: 15-10: 18: 55 \\
12: 28: 24-12: 29: 02\end{array}$ \\
\hline 14 & $15.82^{\circ} \mathrm{E} / 15.88^{\circ} \mathrm{E}$ & $78.19^{\circ} \mathrm{N} / 78.20^{\circ} \mathrm{N}$ & $\begin{array}{l}09: 27: 04-09: 27: 26,09: 56: 23-09: 56: 42 \\
10: 12: 28-10: 12: 48,10: 20: 57-10: 21: 19 \\
12: 18: 56-12: 19: 20,12: 28: 00-12: 28: 23\end{array}$ \\
\hline 15 & $15.94^{\circ} \mathrm{E} / 16.08^{\circ} \mathrm{E}$ & $78.17^{\circ} \mathrm{N} / 78.22^{\circ} \mathrm{N}$ & $\begin{array}{l}09: 25: 43-09: 26: 35,09: 47: 50-09: 48: 43 \\
09: 55: 07-09: 55: 58,10: 13: 10-10: 14: 00 \\
10: 19: 30-10: 20: 25,12: 19: 45-12: 20: 34 \\
12: 26: 45-12: 27: 33\end{array}$ \\
\hline 16 & $16.08^{\circ} \mathrm{E} / 16.18^{\circ} \mathrm{E}$ & $78.17^{\circ} \mathrm{N} / 78.18^{\circ} \mathrm{N}$ & $\begin{array}{l}09: 54: 50-09: 55: 05,10: 14: 12-10: 14: 31 \\
12: 20: 35-12: 20: 55\end{array}$ \\
\hline 17 & $16: 30^{\circ} \mathrm{E} / 16: 45^{\circ} \mathrm{E}$ & $78.19^{\circ} \mathrm{N} / 78.20^{\circ} \mathrm{N}$ & $\begin{array}{l}09: 50: 00-09: 50: 50,09: 52: 59-09: 53: 48 \\
10: 15: 24-10: 16: 15,10: 17: 16-10: 17: 52 \\
12: 21: 52-12: 22: 40,12: 24: 43-12: 25: 28\end{array}$ \\
\hline
\end{tabular}

aerosol layers. Hence, it serves as a reference for a clear background atmosphere.

Profile No 17 is the only observation containing data from a flight segment where the topographic height increased by about $250 \mathrm{~m}$ from near zero at the valley floor to its eastern part. Therefore, measurements at different heights above sea level (ASL) were averaged resulting in the rather thick aerosol layer, as shown in Fig. 5a. The volume depolarization of this particular profile is rather small with maximum values of $\delta_{532 \mathrm{~nm}}^{\mathrm{MAX}} \approx 0.05$ (Fig. $5 \mathrm{~b}$ ). Both other profiles from the eastern part (number 15 and 16) exhibited elevated max- ima of the backscatter ratio at around $500 \mathrm{~m}$ ASL whereby maximum backscatter ratios $R_{532 \mathrm{~nm}}^{\mathrm{MAX}}$ decreased from 15 to about 5 along the mean flow direction toward west.

Inside the Adventdalen the vertical distribution of aerosol particles exhibited a different characteristics (Fig. 5c, d): Large vertical $R_{532} \mathrm{~nm}$-gradients with $R_{532} \mathrm{~nm}>5$ near the surface and values close to 1.4 at the top of the aerosol layer point to a ground source. The volume depolarization $\delta_{532} \mathrm{~nm}$ of the respective profiles (numbers 10-14) was always larger than 0.1 inside the aerosol layer and attained $\delta_{532 \mathrm{~nm}}^{\mathrm{MAX}} \approx 0.3$ near the surface (Fig. 5d). Thus, the backscattering aerosol 


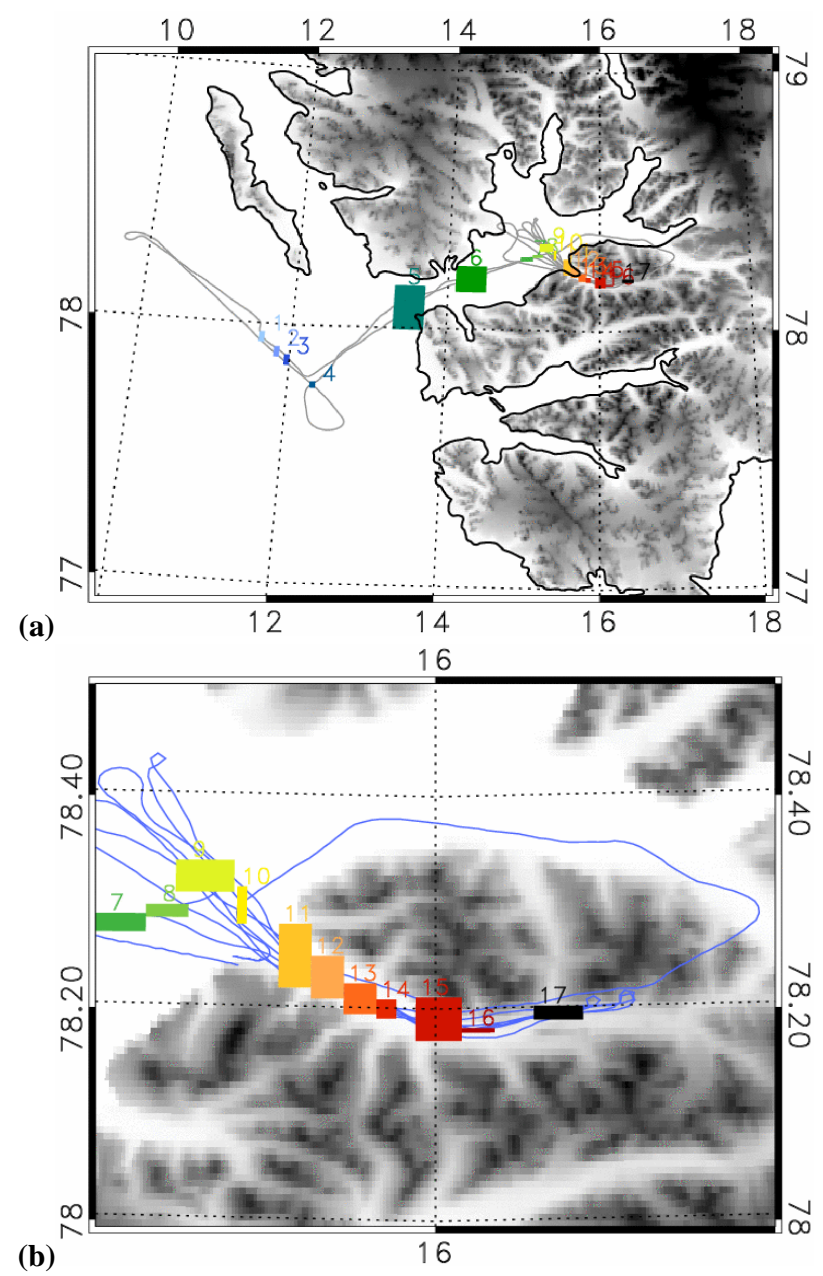

Fig. 4. Locations and sizes of the areas where vertical aerosol backscatter ratio $\left(R_{532} \mathrm{~nm}\right.$, dimensionless $)$ and depolarization $\left(\delta_{532} \mathrm{~nm}\right.$, dimensionless) profiles were taken on 18 May 2004 . The different size of the area corresponds to the area boundaries listed in Table 1. (a) Western Part of Svalbard with the Isfjorden between 14 and $17^{\circ} \mathrm{E}$ and north of $78^{\circ} \mathrm{N}$. (b) Zoom into the Adventdalen which is centred around $16^{\circ} \mathrm{E}$ and $78.2^{\circ} \mathrm{N}$. As listed in Table 1, consecutive periods of the AMALi observations onboard the Polar 2 were used to calculate the averaged $R_{532} \mathrm{~nm}$ and $\delta_{532 \mathrm{~nm}}$-profiles in the respective areas as shown in Figs. 5 and 6: The color code of a particular area refers to the color code of the associated profile.

particles were aspherical and consisted most likely of mineral dust mobilized from the surface of the Adventdalen.

The main mesoscale feature of the profiles inside the Adventdalen is the formation of a mixing layer: The aerosol layer thickened in flow direction along the valley towards the mouth of the Adventdalen, cf. the sequence of $R_{532} \mathrm{~nm}^{-}$ profiles No 14-10 in Fig. 5c. Simultaneously, the verti-

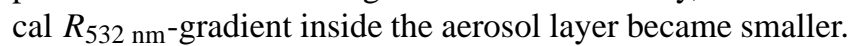
In the given absence of surface heat fluxes, the formation of upright $R_{532 \mathrm{~nm}}$-profiles indicates turbulent mixing in the boundary layer due to shear. Eventually, over the open water of the Isfjorden, a well-mixed $R_{532} \mathrm{~nm}$-profile was established with values between 2 and 3 extending up to about $800 \mathrm{~m}$ altitude (profile No 8 in Fig. 5c). The shape transition of both the $R_{532 \mathrm{~nm}}$ and $\delta_{532 \mathrm{~nm}}$-profiles from the source region inside the valley toward the Isfjorden indicates that the dust particles were transported upward and subsequently mixed due to mechanical turbulence.

The next group of $R_{532} \mathrm{~nm}$ and $\delta_{532} \mathrm{~nm}$-profiles was taken over the open waters of the Isfjorden (Fig. 6a, b). There, the $R_{532 \mathrm{~nm}}$ and $\delta_{532 \mathrm{~nm}}$ profiles No 5-8 still show the characteristics of a well-mixed aerosol layer. However, the height of the aerosol layer declined significantly downstream toward the mouth of the Isfjorden. Additionally, the gradually decreasing $R_{532} \mathrm{~nm}^{-v a l u e s}$ indicate that the dust plume was diluted and dispersed along its way. As the values of $\delta_{532 \mathrm{~nm}}$ were greater than 0.1 inside the aerosol layer, we hypothesize that the observed aerosol particles predominantly consisted of the mineral dust mobilized in the Adventdalen.

However, the exceptionally large $R_{532} \mathrm{~nm}$-values at the location of profile No 9 might tell a different story (Fig. 6a). This particular profile resulted from six overflights in a region which was impacted by the outflow of the Adventdalen, the strong flow past the mountain ridge north of the valley, and the glacier winds blowing over the Isfjorden further north. Thus, both the $R_{532} \mathrm{~nm}$ and the $\delta_{532} \mathrm{~nm}$-profiles at the location No 8 might combine aerosol particles from various sources and the profile is not representative for the dust plume exclusively originating from the Adventdalen.

Finally, the vertical profiles measured over the open sea along the northwest-southeast oriented flight segments allow an estimate of the meridional gradients of the aerosol distribution in the lee of Svalbard, and in particular, downstream of the Isfjorden. Figure $6 \mathrm{c}$ shows four profiles whereby the southernmost profile No 4 exhibits the lowest values of $R_{532 \mathrm{~nm}}<2$ inside the boundary layer. The gradual growth of aerosol backscatter ratio from $R_{532 \mathrm{~nm}} \approx 2 . . .3$ (northernmost profile No 1) to $R_{532 \mathrm{~nm}} \approx 4 \ldots .5$ (profile No 3 ) indicates that the highest aerosol concentration was found downstream of the axis of the Isfjorden (see Fig. 4). The gradual reduction and the more pronounced decay of $R_{532} \mathrm{~nm}$ with altitude toward north points to dilution of the plume due to mixing and sedimentation of the aerosol particles.

The most prominent feature of profile No 3 is the elevated strongly backscattering and depolarising aerosol layer $\left(R_{532 \mathrm{~nm}}^{\mathrm{MAX}}>50, \delta_{532 \mathrm{~nm}}^{\mathrm{MAX}}>1\right)$ at around $600 \mathrm{~m}$ altitude (Fig. 6c, d). Most probably, this layer was produced by drifting ice crystals mobilized by the strong easterly winds at the top of the coastal mountains. It is interesting to note that the southernmost profile No 4 also exhibits a $R_{532} \mathrm{~nm}$-maximum at about $750 \mathrm{~m}$ altitude. If one assumes that these drifting particles were emitted from the peaks of the mountains upstream (about $1200 \mathrm{~m}$ high and in a distance of $200 \mathrm{~km}$ ), a mean airspeed of $10 \mathrm{~m} \mathrm{~s}^{-1}$ results in a rather realistic estimate of the thermal velocity of about $-3 \mathrm{~cm} \mathrm{~s}^{-1}$. 

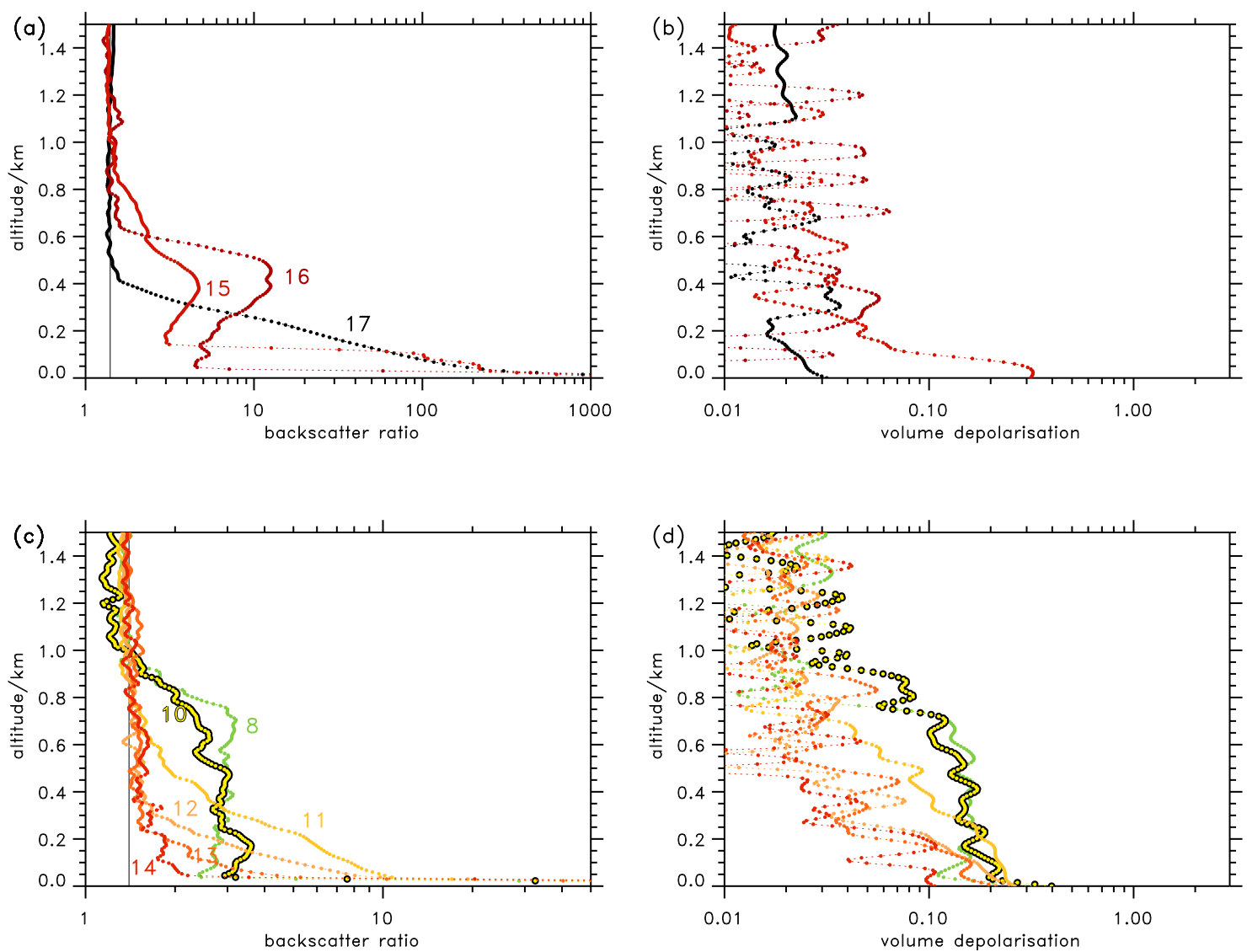

Fig. 5. Backscatter ratio (left column) and volume depolarisation (right column) at $532 \mathrm{~nm}$ inside the Adventdalen as measured along the Polar 2 flight path on 18 May 2004. (a) and (b) depict profiles calculated in areas No 15 to 17 at the eastern part, (c) and (d) profiles calculated in areas No 10 to 14 at the western part of the Adventdalen. Additionally, profile No 8 is added to facilitate the visualisation of the dust plume evolution from the Adventdalen to its exit in the Isfjorden. The color coding refers to the respective segments of the flight path, see Fig. 4 and Table 1.

All profiles observed over the Isfjorden (Fig. 6a, c) show large backscatter values close to the sea surface. Due to the strong easterly winds blowing along the fjord system, sea salt aerosols might be contributing to the total aerosol backscatter as well. In order to investigate the sea salt contribution to the aerosol backscatter separately, two additional flights were performed in the lee of Svalbard which included the predicted high-wind region at the northern tip of Svalbard.

\subsection{Sea salt emissions at the northern tip of Svalbard}

One of the scientific goals of the two flights on 19 and 21 May 2004 was to map the meridional aerosol distribution in the lee of Svalbard under similar meteorological conditions as during the dust storm flight by extending the airborne observations toward north. Especially, we expected a spatial variation of the aerosol distribution from the calm wake region north of the Isfjord toward the predicted coastal low-level jet at the northern tip of Svalbard (see Fig. 1b, c). A secondary goal was the documentation of fate of the dust plume.
Figure 7 shows the time series of the vertical backscatter ratio $R_{532} \mathrm{~nm}$ profiles along those legs which are marked in red in Fig. $1 \mathrm{~b}$ and c, respectively. In each case, the starting point of the flight segments plotted in Fig. 7a, b was located in the warm wake region. In addition to $R_{532} \mathrm{~nm}$, two selected values of the range-corrected signal strength $S$ (for the definition, see Appendix A) were superimposed to mark the presence of strongly backscattering particles, i.e. of clouds in and above the marine boundary layer.

On 19 May 2004, the tropospheric aerosol concentration was generally low with $R_{532 \mathrm{~nm}}^{\mathrm{MAX}} \approx 1.4$ at altitudes greater $1000 \mathrm{~m}$ (Fig. 7a). The origin of the elevated spot with the high backscatter ratio of $R_{532 \mathrm{~nm}} \approx 5.5$ at 10:50 UTC cannot be resolved based on our data. Visual observations from the aircraft as well as satellite imagery as shown in Fig. 2 suggest the absence of visible clouds. However, the large volume depolarisation spot indicates that the cloud consisted most probably of ice particles. 

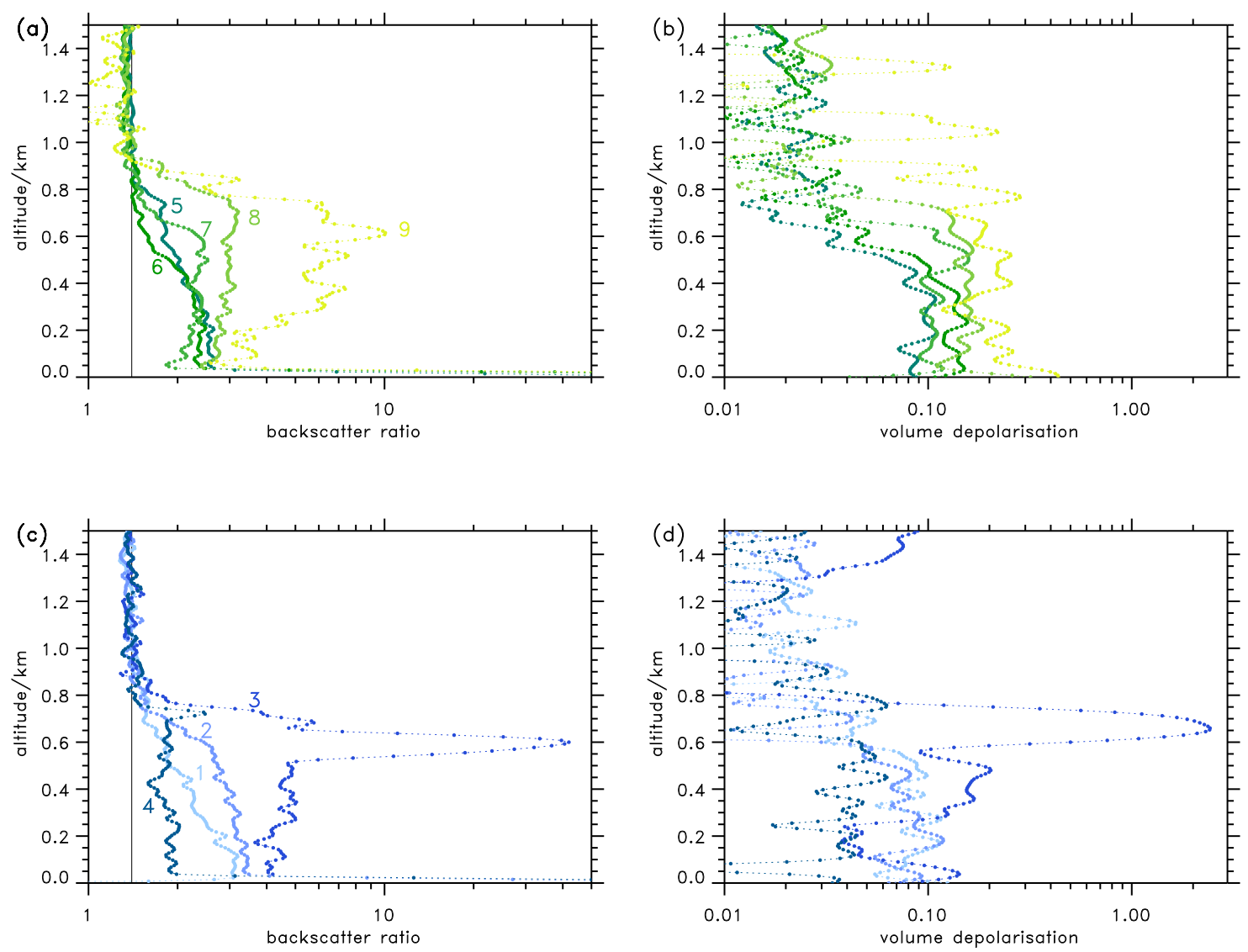

Fig. 6. Backscatter Ratio (left column) and volume depolarisation (right column) at $532 \mathrm{~nm}$ above open water as measured along the Polar 2 flight path on 18 May 2004. (a) and (b) depict profiles calculated in areas No 5 to 9 above the Isfjorden, (c) and (d) profiles calculated in areas No 1 to 4 in the lee of Svalbard. The color coding refers to the respective segments of the flight path, see Fig. 4 and Table 1.

Generally, the aerosol backscatter increased toward the sea surface to values of $R_{532 \mathrm{~nm}} \approx 3$ (Fig. 7a). Backscatter ratio profiles with small vertical $R_{532} \mathrm{~nm}$-gradients and surface values of $R_{532 \mathrm{~nm}}^{\mathrm{MAX}}=2.6$ were mainly measured in the wake region west of Prins Karls Foreland, i.e. between 10:30 and 11:00 UTC. Increased surface values $R_{532} \mathrm{~nm} \approx 4.0$ were only observed in two distinct areas: in the vicinity of the northernmost way point at 10:15 UTC and near the mouth of the Isfjorden (at around 11:15 UTC).

The upward sloping aerosol and cloud layers (enhanced S-values) in the altitude-time cross-section constitute the prominent mesoscale feature of this flight segment (Fig. 7a). The obvious symmetry in the profiles results from the turning point of the aircraft at its northermost way point. This way point was located in the region of the low-level jet, see Fig. 1b. These measurements reveal that the boundary layer height is increasing northward towards the ice edge. The superimposed isentropes (black contour lines in Fig. 7a) of the ECMWF meteorological analyses interpolated on the flight track reproduce the slope of the cloud layer remarkably well. This suggests that the global numerical weather prediction model resolves the unexpected boundary layer height growth in the vicinity of the low-level jet. The nearly vertical isentropes inside the aerosol layer indicate turbulent mixing either by mechanical turbulence (shear in the low-level jet) or by the vertical heat flux (buoyancy production). The processes leading to the sloped boundary layer will be discussed in Sect. 3.3 in conjunction with the mesoscale numerical simulations.

On 19 May 2004 only one overflight across the lowlevel jet was performed (see Fig. 1b). The success of the flight strategy encouraged us to perform a second flight with two consecutive overflights of the jet on 21 May 2004 (see Fig. 1c). The results depicted in Fig. 7b reveal similar mesoscale patterns of the aerosol distribution as found on 19 May 2004. However, as the wind speed was weaker on 21 May 2004 (Fig. 1c), the cloud top height was by about $200 \mathrm{~m}$ lower along the first passage of the low-level jet. Another reason for the lower aerosol layer height is the enhanced thermal stratification (denser isentropic contour lines in Fig. 7b) which suppressed the vertical transport. Besides the lower wind speed on 21 May 2004, the low-level jet 


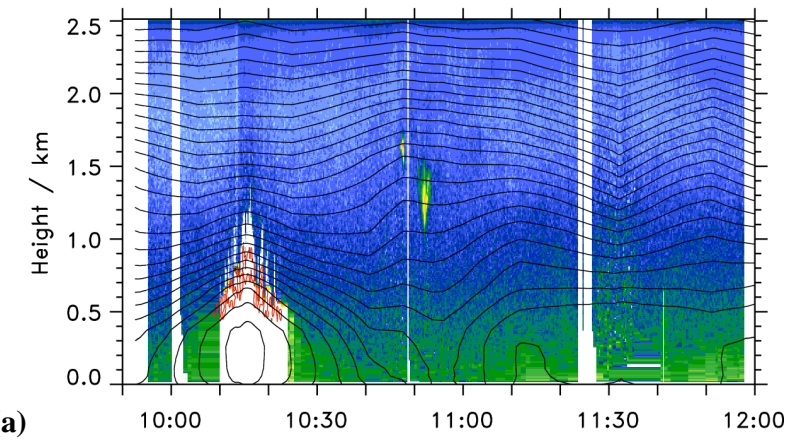

(a)

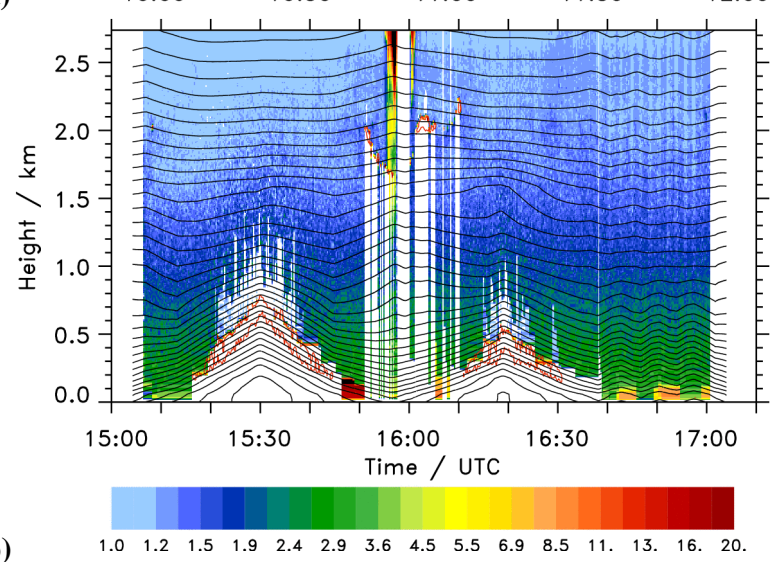

Fig. 7. Backscatter ratio $R_{532} \mathrm{~nm}$ (colour-shaded) and range corrected signal strength $S=P h^{2}=2$ and $4 \cdot 10^{-9}$ (red contour lines) along two flight tracks on 19 May 2004 (a) and on 21 May 2004 (b), respectively. The white areas mark regions with no AMALi data. Black contour lines mark the potential temperature $\Theta$ with $\Delta \Theta=0.5 \mathrm{~K}$ interpolated onto the flight paths (see Fig. 1). Meteorological data from operational $T_{\mathrm{L}} 511 / \mathrm{L} 60 \mathrm{ECMWF}$ analyses.

was also much more curved compared to the conditions on 19 May 2004 (see Fig. 1b and c). Therefore, the variation of the slope and the height of the mesoscale aerosol patterns in downstream direction is difficult to interpret. Furthermore, the northernmost way point of the second intersection of the low-level jet was located further south. Thus, only the difference between the flights on 19 and 21 May 2004 gives evidence that the height of the aerosol layer is directly related to the surface wind speed.

The dependence of the height of the simulated clouds on the horizontal wind speed and the thermal stratification can be also seen in ECMWF's cloud liquid and cloud ice water content as shown in Fig. 8. Enhanced values of the simulated cloud condensate exist in those areas where the lidar measurements detected clouds at the top of the marine boundary layer or at higher levels at around 16:00 UTC on 21 May 2004: The high backscatter ratio above $1500 \mathrm{~m}$ in Fig. $7 \mathrm{~b}$ is most probably related to the clouds simulated by the ECMWF. These clouds are associated with the approaching warm front (compare Figs. 1c and 2b).

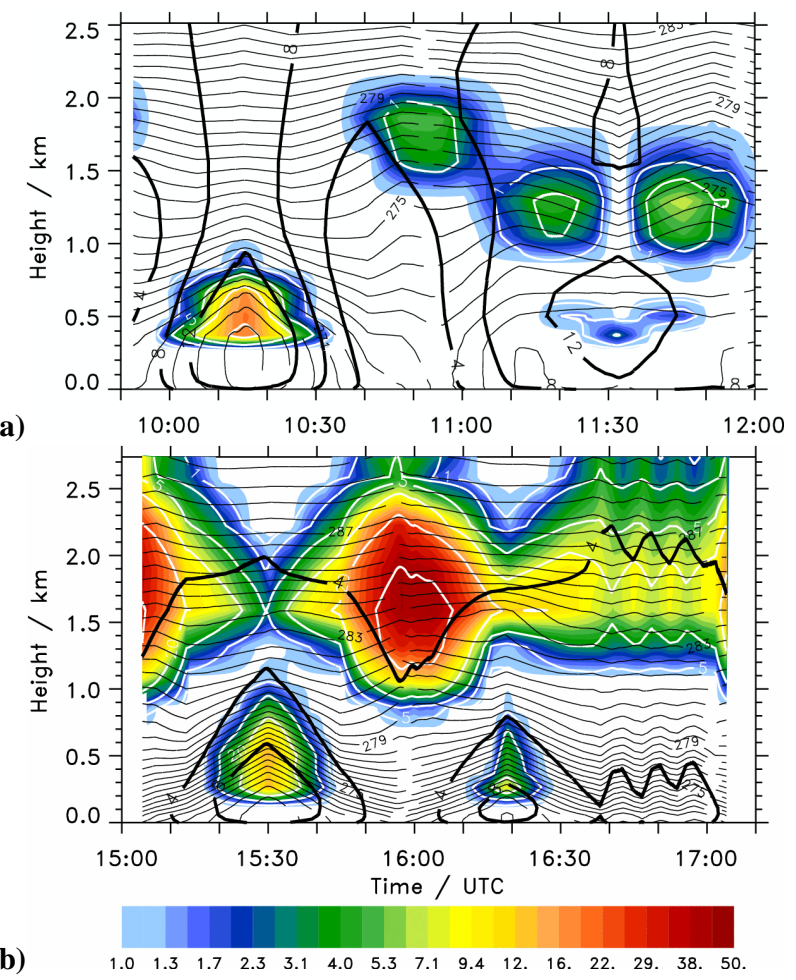

Fig. 8. Cloud liquid water content ( $\mathrm{mg} / \mathrm{kg}$, colour-shaded), cloud ice water content $(\mathrm{mg} / \mathrm{kg}$, white contour lines), horizontal wind speed ( $\mathrm{ms}^{-1}$, thick black lines), and potential temperature $\Theta$ with $\Delta \Theta=0.5 \mathrm{~K}$ interpolated onto the two flight tracks on 19 May 2004 (a) and on 21 May 2004 (b), respectively. Meteorological data from operational $T_{\mathrm{L}} 511 / \mathrm{L} 60$ ECMWF analyses.

It is most likely that the backscattering particles near the sea surface in the northern part of both flights consisted predominantly of sea salt aerosols. This was confirmed by the low depolarisation of the lidar observation (not shown). Further south near the mouth of the Isfjorden, mineral dust constituted a further possible source of aerosol particles. On 19 May 2004, the dust storm in the Adventdalen still persisted, however, to a lesser strength.

\section{Mesoscale numerical simulations}

The observations presented in the preceeding section show characteristic mesoscale features: there was the formation of a well-mixed layer of aerosol particles in the Adventdalen and the sloped aerosol layer at the northern tip of Svalbard. These features are most likely the result of valley flows and of the flow distortion around Svalbard. Furthermore, the backscatter observations indicate at least two different local sources of aerosol particles. In this section, we test the hypothesis that the observed aerosol distribution can be explained by the mobilization of mineral dust and sea salt aerosols. Additionally, the elevated spot of large $R_{532 \mathrm{~nm}}$ and 
$\delta_{532 \mathrm{~nm}}$ values in the lee of the mountains as well as visual observations indicated a strong snow and ice drift during the observation period. Therefore, ice particles emitted from the mountain ranges are considered as well. To support the hypothesis that local sources contributed essentially to the observed aerosol backscatter, we perform mesoscale numerical simulations of the flow past Svalbard including the transport of aerosol particles represented as continuous scalar fields.

\subsection{Setup}

Our numerical experiments were performed with the nonhydrostatic, anelastic model EULAG. An up-to-date comprehensive description of the model and its capabilities can be found in Prusa et al. (2008), Smolarkiewicz and Prusa (2005), and Prusa and Smolarkiewicz (2003). In Appendix $\mathrm{B}$, the governing equations are summarized and the numerical procedure to solve them is described briefly.

In addition to the governing equations for mass, momentum and potential temperature, conservation equations for three passive scalars $C^{\alpha}(\alpha=1,2,3)$ are solved. For our simulations of the mobilization and transport of aerosol particles from and around Svalbard, we assign $\alpha=1$ to the concentration of mineral dust, $\alpha=2$ to that of sea salt, and $\alpha=3$ to ice crystal concentration. In analogy to the turbulent surface fluxes of momentum and heat, we prescribe the turbulent surface flux of the respective scalar species $C^{\alpha}$ into the domain according to:

$q^{\alpha}=\rho_{0} u_{*} c_{*}^{\alpha}, \quad \alpha=1,2,3$

where $\rho_{0}$ is density at the surface, $u_{*}=\kappa v_{T} / \log \left(z_{\operatorname{lm}} / z_{0}\right)$ is the friction velocity with $\kappa=0.41$ as the von Karman constant, $v_{T}$ is the magnitude of the tangential velocity at the lowest model level $z_{1 \mathrm{~m}}$ and $z_{0}$ is the roughness length. The quantity $c_{*}^{\alpha}$ denotes the effective amount of aerosols $C^{\alpha}$ mobilized at the model surface. In analogy to Ničković and Dobričić (1996) we precribe $c_{*}^{\alpha}$ as follows:

$c_{*}^{\alpha}=\left\{\begin{array}{cl}0 & \text { for } u_{*}<u_{\tau}^{\alpha} \\ C_{\mathrm{MAX}}^{\alpha} \min \left[1,\left(\frac{u_{*}}{u_{c}^{\alpha}}\right)^{3}\right] & \text { for } u_{*}>u_{\tau}^{\alpha}, \alpha=1,2,3\end{array}\right.$

where $C_{\mathrm{MAX}}^{\alpha}=\rho^{\alpha} / \rho_{0}$ denotes the capacity of the atmosphere to accept the emitted material with density $\rho^{\alpha}$ from the surface (or, alternatively: the concentration potentially available for mobilization). The velocity $u_{c}^{\alpha}$ comprises a threshold and $u_{\tau}^{\alpha}$ is the velocity at which the mobilization is initiated. Additionally, a thermal velocity of $-0.01 \mathrm{~ms}^{-1}$ is assigned to the vertical velocity transporting the three scalar fields.

As we do not intend to perform a detailed and quantitative microphysical modelling of the aerosol mobilization and dispersion, we prescribe the following values for all scalar species: $u_{c}^{\alpha}=1.2 \mathrm{~ms}^{-1}, u_{\tau}^{\alpha}=0.5 \mathrm{~ms}^{-1}$, and $\rho^{\alpha}=3.210^{-3} \mathrm{~kg} \mathrm{~m}^{-3}$ according to Ničković and Dobričić (1996). However, we restrict the source regions of the three aerosol components in such a way, that sea salt is emitted everywhere over open water south-west of the ice edge and inside the fjords. Dust is exclusively emitted from the Adventdalen, and ice particles are mobilized only over land at altitudes greater than $800 \mathrm{~m}$.

\subsection{Ambient states, initialisation, and boundary conditions}

The governing equations are solved in a quadratic domain $718 \mathrm{~km} \times 718 \mathrm{~km}$ wide and $5 \mathrm{~km}$ high. We use $360 \times 360 \times 51$ grid cells, i.e. $\Delta x=\Delta y=2 \mathrm{~km}$ and $\Delta z=100 \mathrm{~m}$. A realistic topographic model of Svalbard's islands is placed in the centre of the domain (see Fig. 9).

The environmental states for potential temperature $\theta_{e}=\theta_{e}\left(\mathbf{x}_{\mathbf{c}}\right)$, and for the velocity components $\mathbf{v}_{\mathbf{e}}=$ $\left[u_{e}\left(\mathbf{x}_{\mathbf{c}}\right), v_{e}\left(\mathbf{x}_{\mathbf{c}}\right), 0\right]$ are obtained from upstream values of the ECMWF operational analyses at $30^{\circ} \mathrm{E}$ and $79^{\circ} \mathrm{N}$ valid on 19 May 2004 at 12:00 UTC, see the grey lines in Fig. 3. The respective background values for the scalars are set to zero. The initial conditions for the velocity components are $\mathbf{v}_{\mathbf{e}}$ and $\theta^{\prime}=0$. At the lower surface we specify a Neumann boundary conditions for momentum by assuming that the tangential stress is equal to a specified drag force $\tau_{i}$ :

$\tau_{i}=\rho C_{D}\left|v_{T}\right| v_{i}, \quad i=1,2$

where $v_{i}$ are the contravariant velocity components in the $x$ and $y$-directions, respectively and $C_{D}=0.001$ is magnitude of the aerodynamical drag coefficient over flat surfaces and $C_{D}=0.01$ over the rough mountains of Svalbard. Sensitivity experiments have been performed to test the influence of thermal convection over the open water on the aerosol distribution by prescribing a sensible surface heat flux of $40 \mathrm{~W} \mathrm{~m}^{-2}$. At the lateral boundaries the predicted variables are attenuated to their respective environmental states, see Eqs. (B3)-(B7) in Appendix B.

\subsection{Numerical results}

The simulated flow structure is illustrated by means of the horizontal distributions of potential temperature $\Theta$ and horizontal wind speed $V_{\mathrm{H}}$ at $800 \mathrm{~m}$ and $500 \mathrm{~m}$ altitude, respectively, see Fig. 9. After $18 \mathrm{~h}$ of simulation time, the descending flow in the wake region generates a positive temperature anomaly (Fig. 9a). Especially, the downstream development of the $\Theta$-anomaly is in qualitative agreement with the satellite observations as shown in Fig. 2. A better quantitative comparison would require numerical simulations with realistic initial and temporally evolving boundary conditions which is not the aim of our approach. In the numerical simulation with surface heat flux, the warm wake region is wider and extends further downstream compared to the simulations without surface heat flux (not shown). A characteristic feature of the simulated flow field are the numereous low-level 

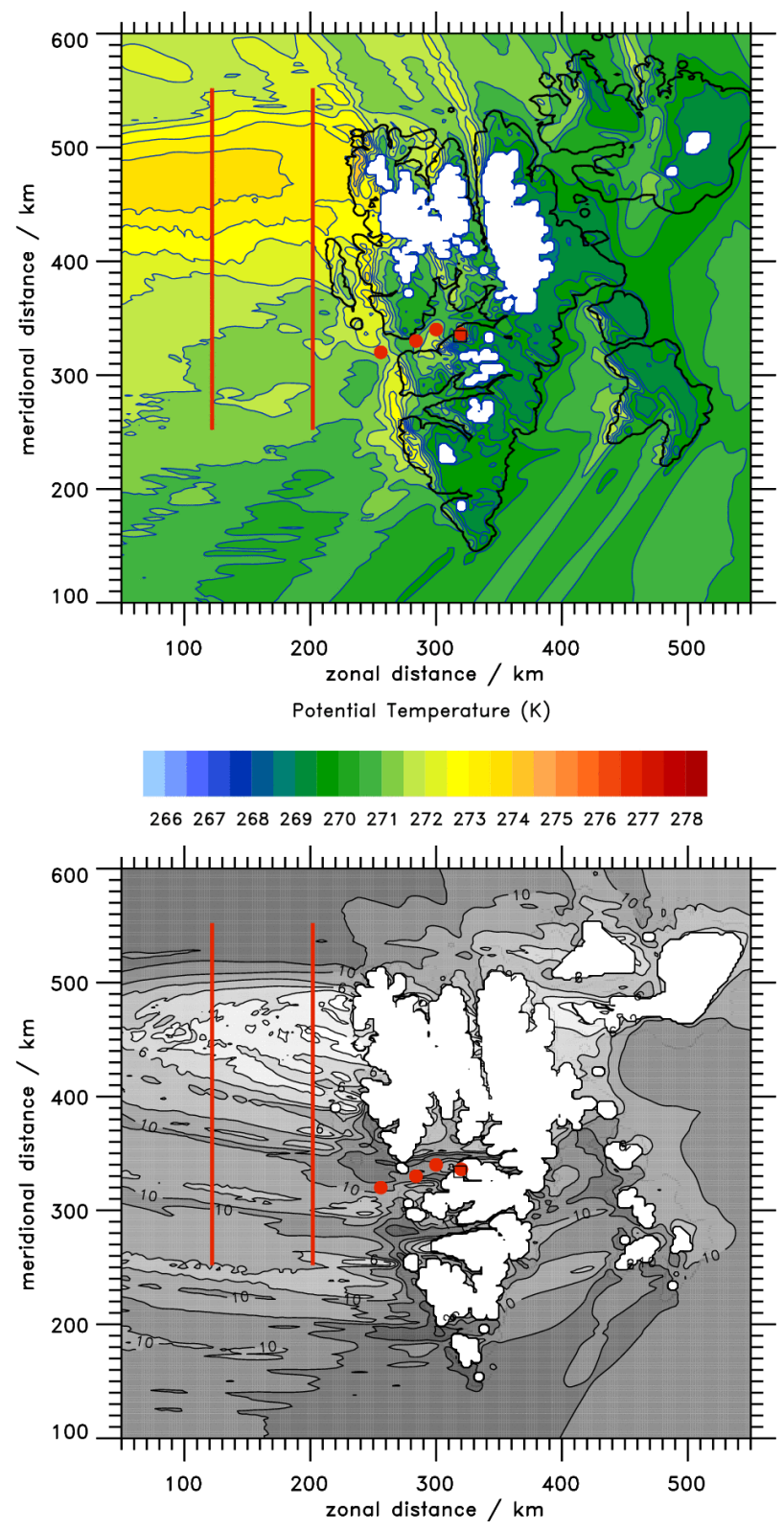

Fig. 9. Simulated potential temperature $\Theta(K, \Delta \Theta=0.5 \mathrm{~K}$, top) at $800 \mathrm{~m}$ altitude and horizontal wind speed $V_{\mathrm{H}}\left(\mathrm{ms}^{-1}\right.$, $\Delta V_{\mathrm{H}}=2 \mathrm{~ms}^{-1}$, bottom) at $500 \mathrm{~m}$ altitude after $18 \mathrm{~h}$ simulation time. Results from a run with surface heat flux. The straight red lines mark the baseline of the vertical sections as shown in Fig. 11, and the red circles the locations of the vertical profiles as shown in Fig. 12.

jets streaming out of the individual fjords on Svalbard's west coast (Fig. 9b).

The associated aerosol distribution after $18 \mathrm{~h}$ simulation time is depicted at $300 \mathrm{~m}$ and $1200 \mathrm{~m}$ altitude in Fig. 10. In the following figures, normalized concentrations $c^{\alpha} / \overline{c^{\alpha}}$ are plotted where the average value $\overline{c^{\alpha}}$ is taken over the whole

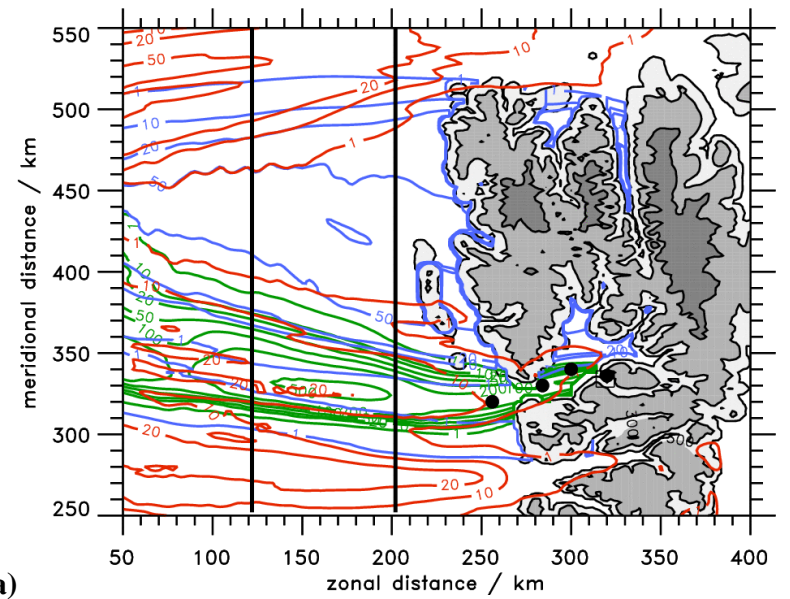

(a)

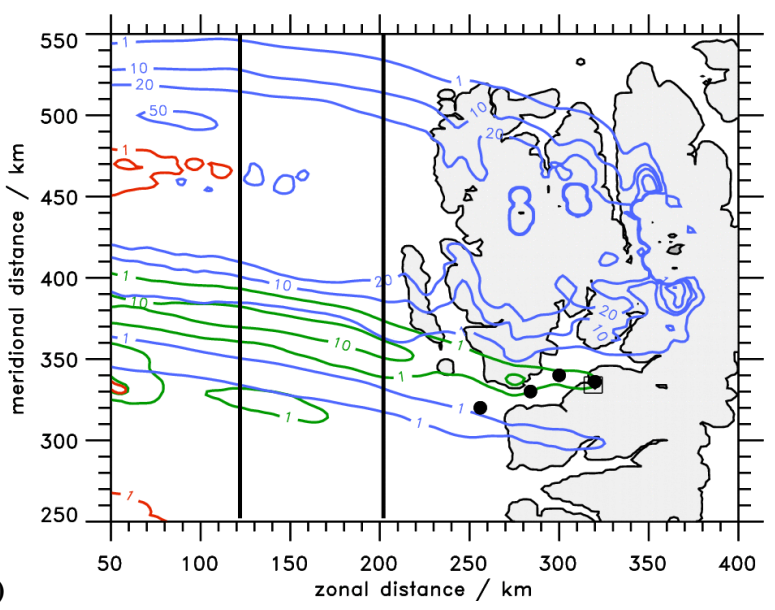

Fig. 10. Horizontal aerosol distribution at $300 \mathrm{~m}$ (a) and $1200 \mathrm{~m}$ altitude (b) after $18 \mathrm{~h}$ simulation time. Results from the run with surface heat flux. The colors of the contour lines denote the different aerosol species: red - sea salt aerosol, green - dust, and blue snow and ice crystals. The straight black lines mark the baseline of the vertical sections as shown in Fig. 11, and the black circles the locations of the vertical profiles as shown in Fig. 12.

domain at the respective time. There are three characteristic features in Fig. 10a: The dust, which was only emitted in the Adventdalen, propagates long distances downstream through the Isfjorden towards the Arctic Ocean. The dust plume broadens markedly towards north and retains a sharp gradient at its southern flank. Secondly, sea salt is emitted everywhere over open water if the friction velocity exceeds the threshold value of $0.5 \mathrm{~ms}^{-1}$. Except in the calm wake region north of the Isfjorden, all other areas are filled with sea salt aerosols. At $300 \mathrm{~m}$ altitude, the strongest meridional gradients are simulated at the northern tip of Svalbard and at the exits of the fjords. A third characteristic feature is the dominance of ice crystals in the wake region. As ice crystals were only emitted at locations higher than $800 \mathrm{~m}$, the presence of the tallest mountains of Svalbard just upstream is the 

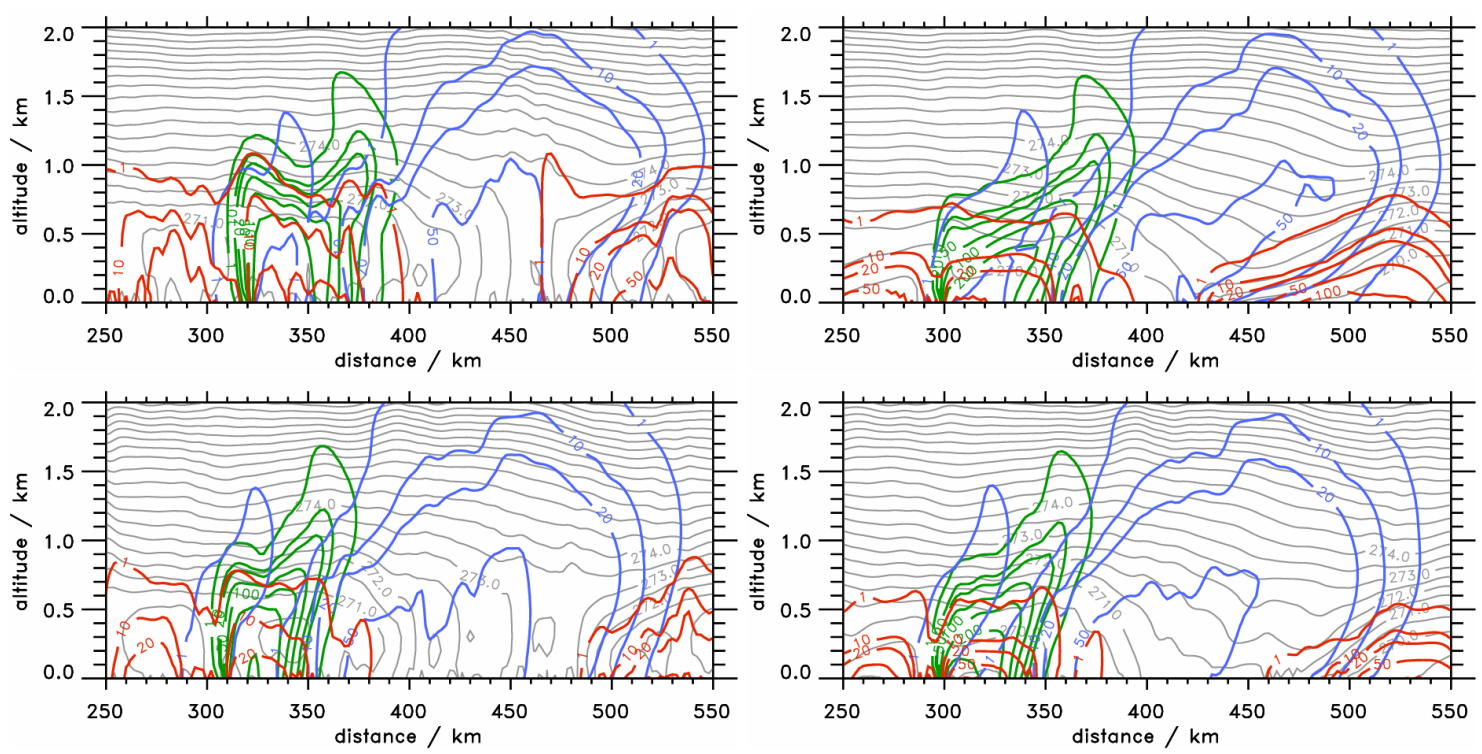

Fig. 11. Vertical aerosol distribution in the lee of Svalbard along the two baselines as shown in Figs. 9 and 10 at $x=122 \mathrm{~km}$ (top row) and $x=202 \mathrm{~km}$ (lower row) after $18 \mathrm{~h}$ simulation time. Left column: results from a run with surface heat flux; right column: results from a run without surface heat flux. The colors of the contour lines denote the different aerosol species: red - sea salt aerosol, green - dust, and blue snow and ice crystals. The black solid lines denote the potential temperature $\Theta(\mathrm{K}, \Delta \Theta=0.5 \mathrm{~K})$.

most probable reason for the concentration maximum in the wake. Secondly, the induced vertical velocities associated with the flow past Svalbard lead to an efficient vertical mixing of the simulated particle concentration. Therefore, ice particles and to a lesser extent also dust is present at $1200 \mathrm{~m}$ altitude as well (Fig. 10b). In effect, only a tenth of the dust concentration can be found at $1200 \mathrm{~m}$ altitude whereas the ice concentration is just a factor 2 smaller compared to the concentration at $300 \mathrm{~m}$ altitude. Based on our numerical simulations, only small amounts of sea salt were transported upward to $1200 \mathrm{~m}$ altitude by convective motions triggered by the positive sensible heat flux (see Fig. 10b).

Figure 11 illustrates the vertical aerosol concentrations by means of two meridional cross sections located about 40 and $100 \mathrm{~km}$ downstream of Svalbard (see the respective baselines in Figs. 9 and 10). There are three regions of interest: Downstream of the Isfjorden (at $y \approx 350 \mathrm{~km}$ in Fig. 11), high concentrations of all species are simulated in the marine boundary layer. In contrast, only ice crystals dominate the simulated aerosol distribution in the wake region (between $y \approx 400$ and $500 \mathrm{~km}$ ). Finally, the numerical simulations reveal an increase of sea salt aerosol concentration in the boundary layer further north at $y>500 \mathrm{~km}$.

Large vertical $\Theta$-gradients at the top of the boundary layer are also reflected in the aerosol plume downstream of the Isfjorden where the concentrations decrease markedly with altitude. The simulated top height of the aerosol layer between $800 \mathrm{~m}$ and $1000 \mathrm{~m}$ is similar to the observed one. Obviously, the top height and the shape of the aerosol plume is influ- enced by the presence of the warmer sea water: the top height increases by about $300 \mathrm{~m}$ in the simulation with surface sensible heat flux. In the simulations with heat flux the aerosol plume is not as much tilted northwards due to the predominant vertical motions in the convective cells. Horizontally, sharp meridional gradients exist towards south whereas the northern flank of the aerosol plume shows a more gradual decrease.

The difference between the numerical simulations with and without sensible surface heat flux is most obvious in the isentropic surfaces in the wake region. In the simulation without surface heating the isentropes bend down due to the adiabatic descent of the air passing over the mountains upstream. With surface heating, even with such small values of $40 \mathrm{~W} / \mathrm{m}^{2}$, a well-mixed boundary layer develops in the numerical simulations which counteracts the adiabatic descent. Although the surface heating influences the shape of the distribution of ice crystals in the wake region it does not influence the magnitude and gross vertical distribution. The absence of sea salt aerosols in the wake region is probably caused by the weak surface wind speed which inhibits the mobilization of sea salt.

There is also an immense influence of the surface heating on the simulated sea salt aerosol distribution in the vicinity of the northern tip of Svalbard: no surface heating leads to sloped contour lines of the sea salt concentration and the shape resembles the observed aerosol backscatter patterns of the lidar measurements (see Fig. 7). On the other hand, the surface heat flux triggers the vertical mixing in the boundary 

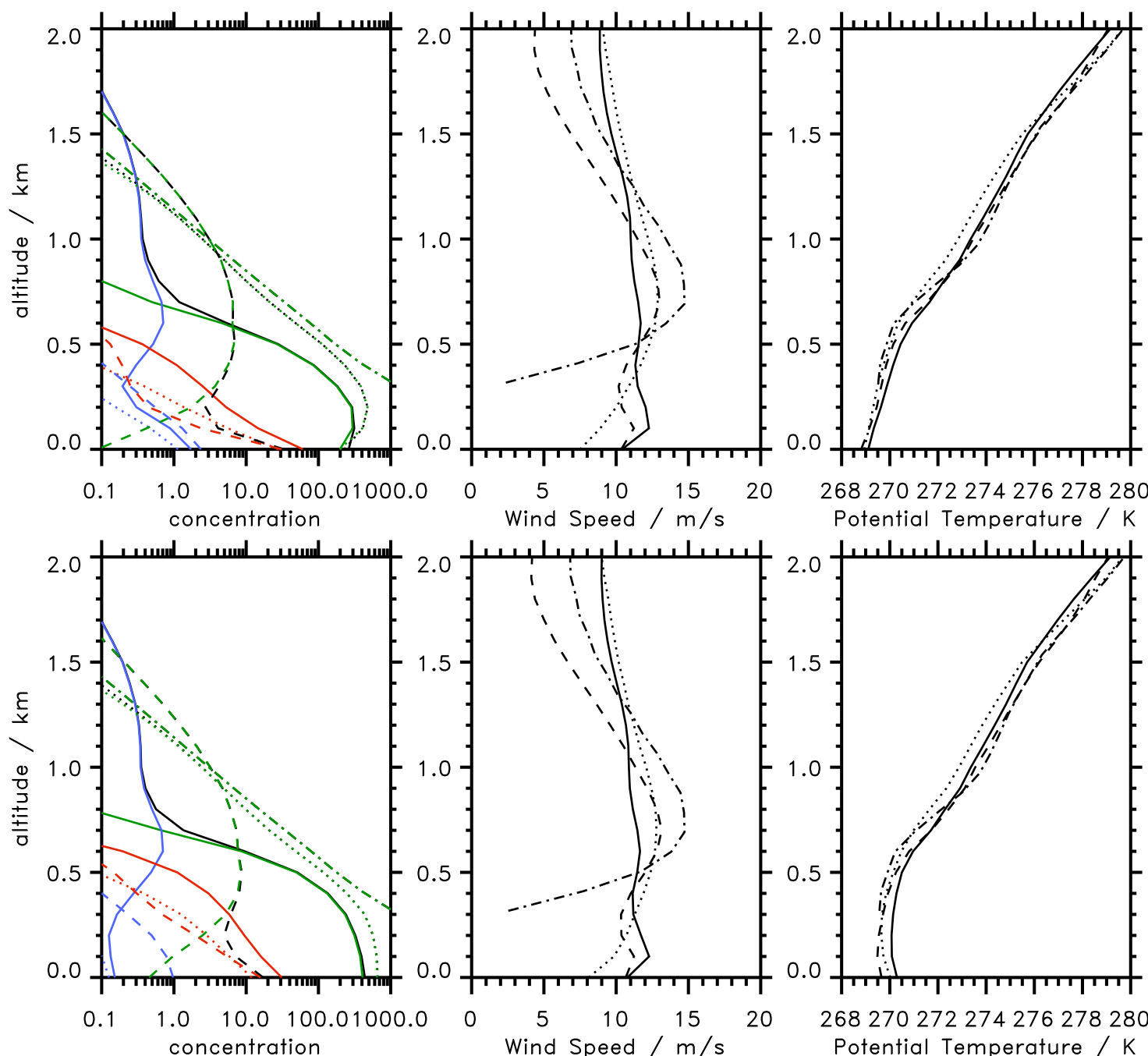

268270272274276278280

Potential Temperature / K

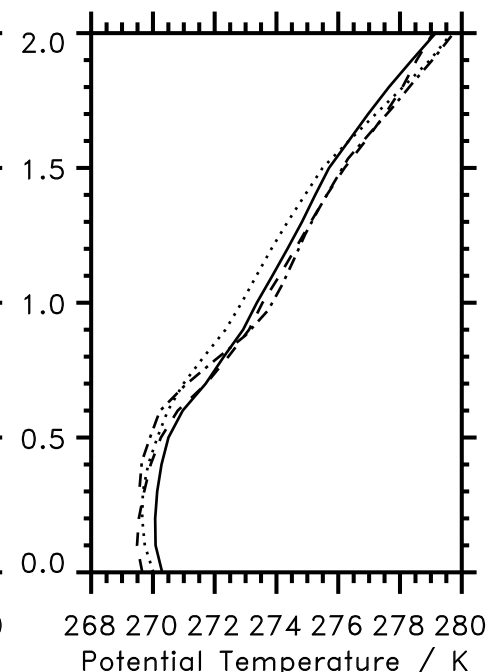

Fig. 12. Vertical profiles of the aerosol concentrations, the magnitude of the horizontal wind speed, and the potential temperature at the marked locations in Figs. 9 and 10 after $18 \mathrm{~h}$ simulation time. The four positions are labeled from west to east in the following order: solid, dotted, dashed, dash-dotted. The colors of the concentration lines denote the different aerosol species: red - sea salt aerosol, green - dust, blue - ice crystals, and black - total concentration. Top row: results from a run without surface heat flux; bottom row: results from a run with surface heat flux.

layer more effectively and leads to an aerosol distribution typical for a convective mixing layer in regions of low $V_{\mathrm{H}}$. Thus, we conclude that the observed sloped aerosol distribution is predominantly caused by the combination of negative vertical motions in the lee of the mountains and the upward motinos in the jet associated with the high wind shear.

Finally, vertical profiles at four selected locations represent the downstream evolution of $\Theta, V_{\mathrm{H}}$, and aerosol concentrations $C_{\alpha}$ along the Isfjorden for the two sets of simulations (Fig. 12). Starting with the easternmost profiles located at the elevated floor inside the Adventdalen (dashdotted lines in Fig. 12), we see that the large surface wind speed mobilizes the dust in the valley. The strong shear $\partial V_{\mathrm{H}} / \partial z$ leads to an effective vertical turbulent mixing of the dust concentration. For this location, the differences between the simulatinos with and without surface flux are marginal. Visual observations during the dust storm in Longyearbyen at 18 May 2004 evidenced that the dust particles from the dry river bed along the valley were rapidly mixed up by the strong and gusty winds.

At the next location - situated in the Isfjorden between the exits of the Adventdalen and the northwards located fjord - (dashed lines in Fig. 12) the integrated effects of the two airstreams can be identified: dust from the Adventdalen retains its maximum concentration between 500 and $1000 \mathrm{~m}$ altitude whereas the flow from the fjord north of the 
Adventdalen carries dust free air which lowers the aerosol concentration at lower levels. Additionally, sea salt aerosol particles are mobilized over the open water which show an exponential decrease with height. The comparison of the aerosol concentration (black dahed line) at this location with the vertical profile No 9 in Fig. 6a reveals an astonishing qualitative similarity.

Differences between the runs with and without surface heat flux are detectable at the positions over the Isfjorden which were selected to be inside the dust plume. Obviously, at these locations the dust concentration is larger below about $600 \mathrm{~m}$ altitude compared to the position at the junction of the both fjords we discussed before. Furthermore, the simulation with the small positive surface heat flux reveal a well-mixed marine boundary layer which is also reflected in the shape of the vertical $\Theta$-profiles. Although, the profiles of the ice concentration exhibit a maximum at around $700 \mathrm{~m}$ altitude, in the numerical simulations dust is still the dominating portion of the overall aerosol concentration.

\section{Discussion and conclusions}

During ASTAR 2004, a quasi-stationary weather situation caused strong easterly winds past Svalbard for a period of about four days. According to Skeie and Grønås (2000), easterly winds dominate during the winter months rather than spring. This exceptional situation mid of May 2004 caused nearly cloud-free conditions in the lee of Svalbard's mountains. Airborne remote-sensing observations above and around the islands were performed to record the aerosol distribution emerging from the impact of the intense easterly winds. To our knowledge, these are the first lidar observations documenting the aerosol distribution in the fjord system and in the lee of Svalbard under such a strongly disturbed weather situation.

The series of airborne lidar observations facilitated a study of the mobilization and the subsequent transport of the different aerosol particles along valleys and the leeside of the islands. For the first time, mesoscale aerosol features associated with the flow over Svalbard could be visualized in the lidar data. Most of the published aerosol lidar observations are performed by ground-based stations under calm high-pressure and clear-sky conditions. Therefore, our airborne remote-sensing observations add new insights about the amount and the spatial distribution of the aerosol particles in the Svalbard area.

Advantageously, the low background concentration of anthropogenic aerosols during this particular period enabled the identification of the sources of the backscattering particles by a combination of remote-sensing observations and mesoscale numerical modelling: Most of the observed backscattering particles were produced by local sources and consisted either of mineral dust, sea salt, or ice crystals. Exceptionally for the time of the year, mineral dust particles were mobi- lized from the surface of the almost snow-free Adventdalen on 18 and 19 May 2004.

Our airborne lidar observations document the upward transport of the dust particles from the surface of the Adventdalen and the formation of a well-mixed aerosol layer along their way toward the open sea (Fig. 5c). The high backscatter values $R_{532 \mathrm{~nm}}>5$ and the volume depolarisation $\delta_{532 \mathrm{~nm}}>10$ indicate the exisitence of mineral dust. The AMALi observations presented in Sects. 2.2 and 2.3 obtain information on aerosol particles larger than approximately $100 \mathrm{~nm}$. The smaller the particle the weaker is its interaction with visible light. However, AMALi still sees the molecular background due to the high number concentration of air molecules. Therefore, a strict lower limit of particle sizes based on the lidar observations cannot be given. For Arctic conditions, aerosol particles smaller than $100 \mathrm{~nm}$ become difficult to detect if their concentration is less than about $1000 \mathrm{~cm}^{-3}$.

The molecular backscattering of the atmosphere at $532 \mathrm{~nm}$ at ground level is about $1.5 \cdot 10^{-6} \mathrm{~m}^{-1} \mathrm{sr}^{-1}$ and proportional to the air density. Assuming Mie theory, one can derive an aerosol size distribution based on lidar observations if simultaneous measurements of the backscatter coefficient at three different wavelengths and the extinction coefficient at two wavelengths were available (Ansmann et al., 1992). Such calculations are challenging and not possible with AMALi output (Stachlewska et al., 2009). Thus, size and concentration of the observed aerosol particles cannot be detangled. Only a rough estimate can be given as follows. A backscatter ratio $R_{532 \mathrm{~nm}} \approx 2$ at $3 \mathrm{~km}$ altitude corresponds to a backscatter coefficient of $1.0 \cdot 10^{-7} \mathrm{~m}^{-1} \mathrm{sr}^{-1}$. This value might be due to 200 particles per $\mathrm{cm}^{3}$ of $0.2 \mu \mathrm{m}$ radius or 10 particles per $\mathrm{cm}^{3}$ of $1 \mu \mathrm{m}$ radius as the scattering efficiency sharply increases with particle radius in this range of sizes.

If we made the assumptions that the aerosol particles had the same size, the same shape and the same chemical composition, then the quantity $\mathrm{R}_{532 \mathrm{~nm}}-1$ is directly proportional to the concentration. However, with the conditions during the ASTAR 2004 flights over the orography of Svalbard the observed aerosol distribution was really complex. There, sea salt, ice crystals and the dust outflow from Adventdalen all entered together in the lidar signal. Our clearest profiles in the calm wake region show $R_{532 \mathrm{~nm}} \approx 2$ close to the ground. If we assume that this value was predominantly due to sea salt we can estimate the extinction coefficient (product of backscatter and lidar ratio) to be about $4.3 \cdot 10^{-5} \mathrm{~m}^{-1}$ at the ground by assuming a lidar ratio of $20 \mathrm{sr}$ according to Doherty et al. (1999). Hence, we obtain a visibility of about $90 \mathrm{~km}$ with the lidar which documents that the unpolluted Arctic atmosphere is really clear.

On the other hand, our high backscatter ratios $R_{532 \mathrm{~nm}} \approx 10$ in the Adventdalen correspond to a particle backscatter of $1.27 \cdot 10^{-5} \mathrm{~m}^{-1} \mathrm{sr}^{-1}$. If we assume a lidar ratio of $55 \mathrm{sr}$ as for desert dust aerosol particles (Ansmann et al., 2008), we obtain a particle extinction of $7.0 \cdot 10^{-4} \mathrm{~m}^{-1}$. If the particles 
were around $0.2 \mu \mathrm{m}$ in radius this roughly corresponded to 7000 particles per $\mathrm{cm}^{3}$. So, this Adventdalen dust event outreached typical Arctic haze events in the vicinity of Spitsbergen. For such haze events, Ritter et al. (2004) report typical values of around 200 particles with $0.2 \mu \mathrm{m}$ radius.

Over the open water of the Isfjorden, the further fate of the dust plume was characterized by dilution as the backscatter ratio was reduced to values of $R_{532 \mathrm{~nm}} \approx 2 \ldots 3$. Due to sedimentation the height of the aerosol plume decreased along its downstream propagation. The formation and evolution of the mixed layer in the Adventdalen is also reflected in the numerical simulations. Besides the dust particles, both the backscatter and the depolarisation measurements as well as the numerical simulations indicate that the marine boundary layer over the Isfjorden contained sea salt and ice particles as well.

Whereas the airborne observations over the Isfjorden on 18 May 2004 reveal a mix of different backscattering aerosol particles, the both airborne lidar observations on 19 and 21 May 2004 in the lee and north of Svalbard identify sea salt as the dominant backscattering aerosol particles inside the marine boundary layer. The numerical simulations reveal that the height of the sea spray depends on the surface wind speed. The characteristic upward slope of the aerosol layer was generated due to the combined action of descending air in the lee of the mountains and the ascent in the low-level jet. The combination of both effects lead to the unsual upward slope of the boundary layer height northward to the ice edge.

Generally, our airborne lidar observations and the numerical simulations indicate that an ubiquitous and significant source of aerosols in the Svalbard area is sea salt which is ejected by different physical processes into the marine boundary layer (see Lewis and Schwartz, 2004; Hara et al., 2003). It is beyond the scope of the present paper to study the sea salt flux in detail as done by Clarke et al. (2006). Extensive remote-sensing and in-situ observations are necessary to undertake such an assessment. However, we point out that sea spray is a significant local source in the Svalbard area when strong surface winds exist. Especially, in years when the sea ice is shifted towards north and the coastal areas are free of ice. But not only the ejection from breaking water waves is a source of sea salt. Recent studies of Yang et al. (2008) have shown that snow lying on sea ice could be a potentially important source of sea salt as well.

It is not clear if local sources play a signficant role in the overall aerosol characteristics in the Svalbard area. Certainly, events like the one presented in this paper do not occur frequently. However, if the meteorological situations are enforcing a strong flow past Svalbard, the aerosol distributions above and around the islands are strongly dependent on local factors as topography, heat content of the water and the upstream wind direction. Climate models often use averaged profiles from stations in the vicinity of orography. How these profiles are to account for topographic effects under certain meteorological conditions remains an open issue. For this reason, it would be worthwhile to have simultaneous quantitative in-situ observations of the aerosol properties in addition to the lidar profile in order to simulate the aerosol evolution with advanced micro-physical models.

\section{Appendix A}

\section{AMALi}

The nadir-aiming eye-safe Airborne Mobile Aerosol Lidar (AMALi) utilized a Nd:Yag laser operating with $15 \mathrm{~Hz}$ repetition rate at a linearly polarised wavelength of $532 \mathrm{~nm}$ and with a pulse energy of $120 \mathrm{~mJ}$. The large laser beam divergence of $2.6 \mathrm{mrad}$ ensured the eye-safety beyond distances greater than $2.5 \mathrm{~km}$ off the system. The parabolic off-axis mirror with a field of view of $3.1 \mathrm{mrad}$ was employed to provide a short range of geometrical compression of $245 \mathrm{~m}$. The range of airborne measurements was limited to the maximum nominal operation height for the laser of $3 \mathrm{~km}$ altitude above sea level. This short vertical range assured sufficiently high signal-to-noise ratio $(\mathrm{SNR}>15)$ and allowed the photomultipliers to operate in an analog mode.

Airborne lidar applications require short integration times in order to achieve sufficient horizontal resolution. During ASTAR 2004, an acceptable SNR was already achieved for an integration time of $1 \mathrm{~s}$ corresponding to a horizontal resolution between $46 \mathrm{~m}$ and $77 \mathrm{~m}$ depending on the aircraft ground speed between $166 \mathrm{kmh}^{-1}(90 \mathrm{kt})$ and $278 \mathrm{kmh}^{-1}$ (150 kt), respectively.

In this paper, we use the following three quantities to characterize the tropospheric aerosol properties: the backscatter ratio $R_{532 \mathrm{~nm}}=\frac{\beta_{\text {part }}+\beta_{\mathrm{mol}}}{\beta_{\mathrm{mol}}}$, whereby $\beta_{\text {part }}$ is the backscatter coefficient due to aerosol particles and $\beta_{\text {mol }}$ the backscatter coefficient due to molecules. A backscatter ratio $R_{532 \mathrm{~nm}}=1$ corresponds to the pure Rayleigh scattering by molecules of the air. In the Arctic, typical $R_{532} \mathrm{~nm}^{-v a l u e s}$ range from $1.01-$ 1.6 for the clear free troposphere.

Secondly, the volume depolarization: The laser in the AMALi emits linearly polarised light at $532 \mathrm{~nm}$. Spherical particles, according to Mie theory, do not alter the state of polarisation, while non-spherical particles almost always do, see: van de Hulst (1981). In AMALi, the returning light from the atmosphere is separated by polarising beam splitter into the components "parallel" and "perpendicular" relative to the laser. We obtain the volume depolarisation $\delta_{532 \mathrm{~nm}}$ as the ratio of the signals "perpendicular" divided by "parallel": $\delta_{532 \mathrm{~nm}}=\frac{\left(\beta_{\text {part }}+\beta_{\mathrm{mol}}\right)_{\perp}}{\left(\beta_{\text {part }}+\beta_{\mathrm{mol}}\right)_{\|}}$. Due to the asphericity of the air molecules, the depolarisation of clean air is $1.4 \%$.

Third, the range-corrected signal strength $S(h)=P(h) \cdot h^{2}$ is used to characterize boundary of cloud layers. Here, $P(h)$ denotes the intensity of the measured current at the range $h$.

All the observed profiles were averaged over $15 \mathrm{~s}$ with range resolution of $7.5 \mathrm{~m}$ and horizontal resolution of $1 \mathrm{~km}$ 
for typical aircraft ground speed of $130 \mathrm{kt}$. The average length of a typical airborne profile varied between 2.5 and $2.7 \mathrm{~km}$ depending on flight altitude and taking into account the losses due to geometrical compression near the lidar.

The backscatter profiles were obtained by a combination of the Klett-Fernald evaluation scheme (Klett,1981, 1985; Fernald, 1984) with the classic Newton-Raphson iterative method, and calibrated with a two-stream algorithm (Stachlewska et al., 2005, Ritter et al., 2006). A detailed description of the AMALi construction, design and evaluation schemes can be found in Stachlewska et al. (2009).

\section{Appendix B}

\section{The numerical model EULAG}

The governing equations are formulated for the Cartesian velocity components $\mathbf{v}=(u, v, w)$ as a function of curvilinear coordinates $(x, y, z)$ which are related to the Cartesian coordinates $\left(x_{c}, y_{c}, z_{c}\right)$ according to the transformation $[x, y, z]=\left[x_{c}, y_{c}, \eta\left(x_{c}, y_{c}, z_{c}\right)\right]$. Here,

$\eta=H \frac{z_{c}-h}{H-h}$

maps the domain above an undulated surface at height $h\left(x_{c}, y_{c}\right)$ and below a plane top surface at $z=H$ onto a rectangular transformed domain. The coordinate transform enters the governing equations of motion through the metric coefficients

$G^{i j}=\sum_{k=1}^{m} \frac{\partial x^{i}}{\partial x_{c}^{k}} \frac{\partial x^{j}}{\partial x_{c}^{k}}$,

and the Jacobian of the transformation $G=\left(\operatorname{det}\left\{G^{i j}\right\}\right)^{-1 / 2}$. The anelastic equations are written in the following form (cf. Smolarkiewicz and Margolin, 1997):

$$
\begin{aligned}
\frac{\partial \rho^{*} u_{i}}{\partial x_{i}} & =0 \\
\frac{d u}{d t} & =-\frac{\partial \pi}{\partial x}-G^{13} \frac{\partial \pi}{\partial z}+f v^{\prime}-\mathcal{D}_{1}(e, \nabla \mathbf{v})-\alpha_{m} u^{\prime} \\
\frac{d v}{d t} & =-\frac{\partial \pi}{\partial y}-G^{23} \frac{\partial \pi}{\partial z}-f u^{\prime}-\mathcal{D}_{2}(e, \nabla \mathbf{v})-\alpha_{m} v^{\prime} \\
\frac{d w}{d t} & =-\frac{1}{G} \frac{\partial \pi}{\partial z}+g \frac{\theta^{\prime}}{\bar{\theta}}-\mathcal{D}_{3}(e, \nabla \mathbf{v})-\alpha_{m} w \\
\frac{d \theta^{\prime}}{d t} & =-v_{j}^{*} \frac{\partial \theta_{e}}{\partial x_{j}}-\mathcal{D}_{\mathrm{H}}(e, \nabla \theta)-\alpha_{\mathrm{H}} \theta^{\prime} \\
\frac{d C^{\alpha}}{d t} & =-\mathcal{D}_{c}^{\alpha}\left(e, \nabla C^{\alpha}\right), \quad \alpha=1,2,3 \\
\frac{d e}{d t} & =\mathcal{S}(e),
\end{aligned}
$$

where $\theta$ is the potential temperature, $C^{\alpha}$ denote the scalar species, $\rho^{*}$ is the reference density $\bar{\rho}$ multiplied by the Ja- cobian of coordinate transformation, $\pi$ is the pressure perturbation with respect to the undisturbed environmental profile normalized by $\bar{\rho}, f$ is the Coriolis parameter, and $g$ is the acceleration due to gravity. The total derivative is given by $d . / d t=\partial . / \partial t+\nabla \cdot\left(\rho^{*}.\right)$ with $\nabla:=(\partial / \partial x, \partial / \partial y, \partial / \partial z)$. Primed variables denote the deviations to an undisturbed environmental state $\theta_{e}, u_{e}$, and $v_{e}$. The attenuation forcings with coefficients $\alpha_{m}$ and $\alpha_{\mathrm{H}}$ appearing in the momentum and entropy equations simulate wave-absorbing devices in the vicinity of the open lateral boundaries of the numerical model.

The $\mathcal{D}$-terms appearing in the above equations symbolize viscous dissipation of momentum, diffusion of heat and species via the divergence of turbulent stresses and fluxes of heat and species, respectively.

$$
\begin{aligned}
\mathcal{D}_{i} & =\frac{\partial \tau_{i j}}{\partial x_{j}}, \quad \tau_{i j}=2 \rho K_{M}\left(e_{i j}-\frac{1}{3} \delta^{i j} e_{k k}\right), \\
\mathcal{D}_{\mathrm{H}} & =\rho K_{\mathrm{H}} \delta^{i j} \frac{\partial \theta}{\partial x_{j}} \\
\mathcal{D}_{c}^{\alpha} & =\rho K_{\mathrm{H}} \delta^{i j} \frac{\partial C^{\alpha}}{\partial x_{j}}
\end{aligned}
$$

where

$e_{i j}=\frac{1}{2}\left(\frac{\partial u_{i}}{\partial x_{j}}+\frac{\partial u_{j}}{\partial x_{i}}\right)$

is the rate-of-strain tensor. For a detailed description of the diffusive terms in time-dependent curvilinear coordinates, see Prusa and Smolarkiewicz (2003). The corresponding eddy coefficients $K_{M}$ and $K_{\mathrm{H}}$ are proportional to the square root of the turbulent kinetic energy $e$. In the subgrid-scale (SGS) model all sources and sinks of $e$ are combined in $\mathcal{S}(e)$; see Sorbjan 1996 and Margolin et al., 1999 for details of the SGS-model.

The governing equations are solved by means of finitedifference approximations using a second-order accurate nonoscillatory forward-in-time (NFT) approach (Smolarkiewicz and Margolin, 1997; Smolarkiewicz and Prusa, 2005). The prognostic equations are written compactly in a conservation-law form

$\frac{\partial \rho^{*} \Psi}{\partial t}+\nabla \cdot\left(\rho^{*} \mathbf{v} \Psi\right)=\rho^{*} R^{\Psi}$,

where $\Psi$ symbolizes the velocity components $u, v$, and $w$, the passive scalars $\mathrm{C}^{\alpha}$, the potential temperature $\theta$ or the turbulent kinetic energy $e$. On a discrete mesh, the NFT approximation of Eq. (B14) can be written as

$\Psi_{\mathbf{i}}^{n+1}=L E_{\mathbf{i}}(\tilde{\Psi})+\left.0.5 \Delta t R^{\Psi}\right|_{\mathbf{i}} ^{n+1}$,

where $\Psi_{\mathbf{i}}^{n+1}$ denotes the solution at the grid point $\left(t^{n+1}, \mathbf{x}_{\mathbf{i}}\right)$, $\widetilde{\Psi}:=\Psi^{n}+\left.0.5 \Delta t R^{\Psi}\right|^{n}$, and $L E$ denotes the NFT transport operator. In the Eulerian scheme, used exclusively in this paper, $L E$ integrates the homogeneous transport Eq. (B14) - 
viz., $L E$ advects $\widetilde{\Psi}$ using a fully second-order-accurate fluxform scheme MPDATA (for a review, see Smolarkiewicz and Margolin, 1998).

The SGS forcings included in $R^{\Psi}$ are evaluated explicitly and to the first order. This is justified because the $\mathcal{D}$-terms enter the governing equations only as a consequence of a SGS turbulence model, i.e. already as a correction $\mathcal{O}(\Delta x)$. Technically, this eliminates the need for predecting $\mathrm{SGS}^{n+1}$ in $\left.R^{\Psi}\right|^{n+1}$ on the rhs of Eq. (B15), as $\operatorname{SGS}\left(\Psi^{n+1}\right)=\operatorname{SGS}\left(\Psi^{n}\right)+\mathcal{O}(\Delta t)$. Technically, the definition of the auxiliary field $\widetilde{\Psi}$ is expanded as $\widetilde{\Psi}:=\Psi^{n}+$ $0.5 \Delta t\left(\left.R_{\mathrm{inv}}^{\Psi}\right|^{n}+\left.2 R_{\mathrm{SGS}}^{\Psi}\right|^{n}\right)$. Here, the resolved inviscid forcings are accounted for in $\left.R_{\text {inv }}^{\Psi}\right|^{n}$ in $\left.R^{\Psi}\right|^{n+1}$ on the rhs of Eq. (B15); refer to Sects. 3.5.4 and 4.3 in Smolarkiewicz and Margolin (1998). The explicit first-order evaluation of the SGS forcings improves the efficacy of the numerical calculations.

In the implicit option of the model algorithm, $\Psi \equiv \theta^{\prime}$ the entropy equation is solved simultaneously with the momentum equations - via formulating and solving an elaborate elliptic problem for pressure, cf. Smolarkiewicz et al. (2004) for discussion - whereupon the buoyancy term is integrated implicitly over $t \in\left[t^{n}, t^{n+1}\right]$ using the trapezoidal rule (see Dörnbrack et al., 2005).

Acknowledgements. Andreas Dörnbrack acknowledges the reliable access to the ECMWF forecast and analysis data through the Special Project "Influence of non-hydrostatic gravity waves on the stratospheric flow field above Scandinavia". For the technical support during the ASTAR campaign we want to acknowledge the companies enviscope GmbH and OPTIMARE GmbH. Special thanks to the DLR pilots who made the flights according our plans. The stimulating discussions with P. K. Smolarkiewicz and P. Ortiz in Boulder about the saltation and transport of sand are very much appreciated. We thank anonymous reviewers who made important comments which strengthened the manuscript.

Edited by: A. Minikin

\section{References}

Ansmann, A., Wandinger, U., Riebesell, M., Weitkamp, C., and Michaelis, W.: Independent measurement of extinction and backscatter profiles in cirrus clouds by using a combined Raman elastic-backscatter lidar, Appl. Opt., 31, 7113-7113, 1992.

Ansmann, A., Tesche, M., Althausen, D., Müller, D., Seifert, P., Freudenthaler, V., Heese, B., Wiegner, M., Pisani, G., Knippertz, P., and Dubovik, O.: Influence of Saharan dust on cloud glaciation in southern Morocco during the Saharan Mineral Dust Experiment, J. Geophys. Res., 113, D04210, doi:10.1029/2007JD008785, 2008.

Clarke, A. D., Owens, S. R., and Zhou, J.: An ultra-fine sea-salt flux from breaking waves: Implications for cloud condensation nuclei in the remote marine atmosphere, J. Geophys. Res., 111, D06202, doi:10.1029/2005JD006565, 2006.
Dörnbrack, A., Doyle, J. D., Lane, T. P., Sharman, R. D., and Smolarkiewicz, P. K.: On physical realizability and uncertainty of numerical solutions, Atmos. Sci. Lett., 6, 118-122, 2005.

Doherty, S. J., Anderson, T. L., and Charlson, R. J.: Measurement of the Lidar Ratio for Atmospheric Aerosols with a $180^{\circ}$ Backscatter Nephelometer, Appl. Opt., 38, 1823-1832, 1999.

Doyle, J. D. and Shapiro, M. A.: Flow response to large-scale topography: the Greenland tip jet, Tellus, 51A, 728-748, 1999.

Engvall, A.-C., Krejci, R., Ström, J., Minikin, A., Treffeisen, R., Stohl, A., and Herber, A.: In-situ airborne observations of the microphysical properties of the Arctic tropospheric aerosol during late spring and summer, Tellus B, 60, 392-404, 2008.

Fernald, F. G.: Analysis of atmospheric lidar observations: some comments, App. Opt., 23, 652-653, 1984.

Garrett, T. J., Radke, L. F., and Hobbs, P. V.: Aerosol effects on cloud emissivity and surface longwave heating in the Arctic, J. Atmos. Sci., 59, 769-778, 2002.

Hara, K., Yamagata, S., Yamanouchi, T., Sato, K., Herber, A., Iwasaka, Y., Nagatani, M., and Nakata, H.: Mixing states of individual aerosol particles in spring Arctic troposphere during ASTAR 2000 campaign, J. Geophys. Res., 108(D7), 4209, doi:10.1029/2002JD002513, 2003.

Hoffmann, A., Ritter, C., Stock, M., Shiobara, M., Lampert, A., Maturilli, M., Orgis, T., Neuber, R., and Herber, A.: Ground-based lidar measurements from Ny-Ålesund during ASTAR 2007, Atmos. Chem. Phys., 9, 9059-9081, 2009,

http://www.atmos-chem-phys.net/9/9059/2009/.

van de Hulst, H. C.: Light scattering by small particles, New York: Dover, 1981.

Klett, J. D.: Stable analytical inversion solution for processing lidar returns, App. Opt., 20, 211-220, 1981.

Klett, J. D.: Lidar inversions with variable backscatter/extinction values, App. Opt., 24, 211-220, 1985.

Lewis, E. R. and Schwartz, S. E.: Sea Salt Aerosol Production: Mechanisms, Methods, Measurements, and Models - A Critical Review, American Geophysical Union, Washington, DC, Geophysical Monograph, 152, 413 pp., 2004.

Lubin, D. and Vogelmann, A. M.: A climatologically signifant aerosol longwave indirect effect in the Arctic, Nature, 439, 453456, 2006.

Margolin, L. G., Smolarkiewicz, P. K., and Sorbjan, Z.: Large-eddy simulations of convective boundary layers using nonoscillatory differencing, Physica D, 133, 390-397, 1999.

Ničković, S. and Dobričić, S.: A model for long- range transport of desert dust, Mon. Weather Rev., 124, 2537-2544, 1996.

Orr, A., Hunt, J., Capon, R., Sommeria, J., Cresswell, D., and Owinoh, A.: Coriolis effects on wind jets and cloudiness along coasts, Weather, 60, 291-299, 2005.

Pickart, R. S., Spall, M. A., Ribergaard, M. H., Moore, G. W. K., and Milliff, R. F.: Deep convection in the Irminger Sea forced by the Greenland tip jet, Nature, 424, 152-156, 2003.

Pierrehumbert, R. T.: Stratified ageostrophic flow over twodimensional topography in an unbounded atmosphere, J. Atmos. Sci., 42, 523-526, 1985.

Prusa, J. M. and Smolarkiewicz, P. K.: An all-scale anelastic model for geophysical flows: dynamic grid deformation, J. Comp. Phys., 190, 601-622, 2003.

Prusa, J. M., Smolarkiewicz, P. K., and Wyszogradski, A. A.: EU- 
LAG, a computational model for multiscale flows, Computer \& Fluids, 37, 1193-1207, 2008.

Radke, L. F., Lyons, J. H., Hegg, D. A., Hobbs, P. V., and I. H. Bailey: Airborne observations of arctic aerosols.1: Characteristics of Arctic haze, Geophys. Res. Lett., 11, 393-396, 1984.

Rinke, A., Dethloff, K., and Fortmann, M.: Regional climate effects of Arctic haze, Geophys. Res. Lett., 31, L16202, doi:10.1029/2004GL020318r, 2004.

Ritter, C., Kirsche, A., and Neuber, R.: Tropospheric aerosol characterized by a Raman lidar over Spitsbergen, ILRC22, ESA SP561, 459-462, 2004.

Ritter C., Notholt, J., Fischer, J., and Rathke, C.: Direct thermal radiative forcing of tropospheric aerosol in the Arctic measured by ground based infrared spectrometry, Geophys. Res. Lett., 32, L23816, doi:10.1029/2005GL024331, 2005.

Ritter, C., Stachlewska, I. S., and Neuber, R.: Application of the two-stream evaluation for a case study of Arctic Haze over Spitsbergen, in Proceedings of 23nd International Laser Radar Conference (ILRC 2006 in Nara, Japan), edited by: Nagasawa, C. and Sugimoto, N., 1, 507-510, ISBN 4-9902916-0-3, 2006.

Sandvik, A. D. and Furevik, B. R.: Case study of a coastal jet at Spitsbergen - Comparison of SAR- and model-estimated wind, Mon. Weather Rev., 130, 1040-1051, 2002.

Schär, C.: Mesoscale mountains and the large-scale atmospheric dynamics: A review, in: Meteorology at the Millenium, Academic Press, 29-42, 2002.

Schnell, R. C.: Arctic haze and the ARCTIC GAS AND AEROSOL SAMPLING PROGRAM (AGASP), Geophys. Res. Lett., 11, 361-364, 1984.

Schnell, R. C., Barry, R. G., Miles, M. W., Andreas, E. L., Radke, L. F., Brockm C. A., McCormick, M. P., and Moore, J. L.: Lidar detection of leads in Arctic sea ice, Nature, 359, 530-532, 1989.

Schwartz, S. E. and Andreae, M. O.: Uncertainty in climate change caused by aerosols, Science, 272, 1121-1122, 1996.

Skeie, P. and Grønås, S.: Strongly stratified easterly flows across Spitsbergen, Tellus, 52A, 473-486, 2000.

Smolarkiewicz, P. K. and Margolin, L. G.: On forward-in-time differencing for fluids: An Eulerian/semi-Lagrangian nonhydrostatic model for stratified flows, Atmos. Ocean Special, 35, 127$152,1997$.

Smolarkiewicz, P. K. and Margolin, L. G.: MPDATA: A finitedifference solver for geophysical flows, J. Comput. Phys., 140, 459-480, 1998.
Smolarkiewicz, P. K., Temperton, C., Thomas, S. J., and Wyszogrodzki, A. A.: Spectral Preconditioners for nonhydrostatic atmospheric models: extreme applications, ECMWF Seminar Series on Recent developments in numerical methods for atmospheric and ocean modelling, 6-10 September 2004, Reading, UK (online: http://www.ecmwf.int/publications/library), 2004.

Smolarkiewicz, P. K. and Prusa, J. M.: Towards mesh adaptivity for geophysical turbulence: contininous mapping approach, Int. J. Numer. Meth. Fluids, 47, 789-801, 2005.

Sorbjan, Z.: Numerical study of penetrative and "solid lid" nonpenetrative convective boundary layers. J. Atmos. Sci., 53, 101-112, 1996.

Stachlewska, I. S., Ritter, C., and Neuber, R.: Application of the two-stream inversion algorithm for retrieval of extinction, backscatter and lidar ratio for clean and polluted Arctic air, in Proceedings of SPIE, 5584, 03/1-03/8, 2005.

Stachlewska, I. S., Neuber, R., Lampert, A., Ritter, C., and Wehrle, G.: AMALi - the Airborne Mobile Aerosol Lidar for Arctic research, Atmos. Chem. Phys. Discuss., 9, 18745-18792, 2009, http://www.atmos-chem-phys-discuss.net/9/18745/2009/.

Thomason, L. W., Herber, A. B., Yamanouchi, T., and Sato, K.: Arctic study on tropospheric aerosol and radiation: comparison of tropospheric aerosol extinction profiles measured by airborne photometer and SAGE II, Geophys. Res. Lett., 30, L1328, doi:10.1029/2002GL016453, 2003.

Treffeisen, R., Herber, A., Ström, J., Shiobara, M., Yamanouchi, T., Yamagata, S., Holmen, K., Kriews, M., and Schrems, O.: Interpretation of Arctic aerosol properties using cluster analysis applied to observations in the Svalbard area, Tellus, 56B, 457476, 2004.

Yamanouchi, T., Treffeisen, R., Herber, A., Shiobara, M., Yamagata, S., Hara, K., Sato, K., Yabuki, M., Tomikawa, Y., Rinke, A., Neuber, R., Schumacher, R., Kriews, M., Ström, J., Schrems, O., and Gernhardt, H.: Arctic study of tropospheric aerosol and radiation (ASTAR) 2000: Arctic haze case study, Tellus, 57B, 141-152, 2005.

Yang, X., Pyle, J. A., and Cox, R. A.: Sea salt aerosol production and bromine release: Role of snow on ice, Geophys. Res. Lett., 35, L16815, doi:10.1029/2008GL034536, 2008. 